This is an electronic reprint of the original article. This reprint may differ from the original in pagination and typographic detail.

Author(s): Knoppe, Stefan; Häkkinen, Hannu; Verbiest, Thierry; Clays, Koen

Title: $\quad$ The Role of Donor and Acceptor Substituents on the Nonlinear Optical Properties of Gold Nanoclusters

Year: $\quad 2018$

Version:

Please cite the original version:

Knoppe, S., Häkkinen, H., Verbiest, T., \& Clays, K. (2018). The Role of Donor and Acceptor Substituents on the Nonlinear Optical Properties of Gold Nanoclusters. Journal of Physical Chemistry C, 122(7), 4019-4028.

https://doi.org/10.1021/acs.jpcc.7b12356

All material supplied via JYX is protected by copyright and other intellectual property rights, and duplication or sale of all or part of any of the repository collections is not permitted, except that material may be duplicated by you for your research use or educational purposes in electronic or print form. You must obtain permission for any other use. Electronic or print copies may not be offered, whether for sale or otherwise to anyone who is not an authorised user. 


\section{The Role of Donor and Acceptor Substituents on the Nonlinear Optical Properties of Gold Nanoclusters}

Stefan Knoppe, Hannu Häkkinen, Thierry Verbiest, and Koen Clays

J. Phys. Chem. C, Just Accepted Manuscript • DOI: 10.1021/acs.jpcc.7b12356 • Publication Date (Web): 30 Jan 2018

Downloaded from http://pubs.acs.org on January 31, 2018

\section{Just Accepted}

"Just Accepted" manuscripts have been peer-reviewed and accepted for publication. They are posted online prior to technical editing, formatting for publication and author proofing. The American Chemical Society provides "Just Accepted" as a free service to the research community to expedite the dissemination of scientific material as soon as possible after acceptance. "Just Accepted" manuscripts appear in full in PDF format accompanied by an HTML abstract. "Just Accepted" manuscripts have been fully peer reviewed, but should not be considered the official version of record. They are accessible to all readers and citable by the Digital Object Identifier (DOI®). "Just Accepted" is an optional service offered to authors. Therefore, the "Just Accepted" Web site may not include all articles that will be published in the journal. After a manuscript is technically edited and formatted, it will be removed from the "Just Accepted" Web site and published as an ASAP article. Note that technical editing may introduce minor changes to the manuscript text and/or graphics which could affect content, and all legal disclaimers and ethical guidelines that apply to the journal pertain. ACS cannot be held responsible for errors or consequences arising from the use of information contained in these "Just Accepted" manuscripts. 


\title{
The Role of Donor and Acceptor Substituents on the Nonlinear Optical Properties of Gold Nanoclusters
}

\author{
Stefan Knoppe, ${ }^{1,2} *$ Hannu Häkkinen, ${ }^{3}$ Thierry Verbiest ${ }^{1}$ and Koen Clays ${ }^{1}$ \\ 1: Department of Chemistry, KU Leuven, Celestijnenlaan 200D, 3001 Leuven, Belgium \\ 2: Institute for Physical Chemistry, University of Stuttgart, Pfaffenwaldring 55, 70569 \\ Stuttgart, Germany \\ 3: Departments of Chemistry and Physics, Nanoscience Center, University of Jyväskylä, \\ 40014 Jyväskylä, Finland \\ *: stefan.knoppe@ipc.uni-stuttgart.de
}




\begin{abstract}
In recent years, a large number of monolayer-protected clusters (MPCs) has been studied by means of single crystal structure characterization. A central aspect of research on MPCs is the correlation of their interesting optical properties with structural features and the formulation of a theoretical framework that allows interpretation of their unique properties. For this, superatom and jellium models have been proven successful. Little attention, however, has been paid to the influence of the protecting ligands. Here, we investigate the effect of changes in $\left[\mathrm{Au}_{25}(\mathrm{SR})_{18-\mathrm{x}}\left(\mathrm{SR}^{\prime}\right)_{\mathrm{x}}\right]^{-}$, where $\mathrm{SR}^{\prime}$ represents a parasubstituted thiophenolate derivative $(\mathrm{SPh}-4-\mathrm{X})$. We computed the first hyperpolarizabilities, screening a broad range of substituents $\mathrm{X}$. For $\left[\mathrm{Au}_{25}(\mathrm{SR})_{17}\left(\mathrm{SR}^{\prime}\right)_{1}\right]^{-}$ clusters, significant first hyperpolarizabilities were calculated, spanning two orders of magnitude depending on $\mathrm{X}$. A strong dependence on the electron-donating/withdrawing properties of the substituent was found for para-substituted thiophenol ligands. Protonation of amine substituents leads to a change from donor to acceptor substitution, leading to a record setting contrast for nonlinear optical proton sensing. Furthermore, 'push/pull' systems were considered where both an acceptor and a donor ligand were positioned at opposite ends of the cluster. This induces significant increase of the first hyperpolarizability through charge transfer. Overall, our results indicate that the right choice of ligand can significantly impact the (nonlinear) optical properties of MPCs. This adds a new component to the cluster chemist's toolbox.
\end{abstract}




\section{Introduction}

Monolayer-protected metal clusters (MPCs) are intriguing compounds due to their nonscalable geometric and electronic structures, going along with molecule-like properties such as featured absorption and circular dichroism spectra, tunable HOMO-LUMO gaps and magnetic properties. ${ }^{1,2}$ While MPCs in general can be prepared with good stability and atomic precision with coinage metals $\left(\mathrm{Cu},{ }^{3} \mathrm{Ag},{ }^{4-11} \mathrm{Au}^{12-20}\right)$ or alloys of noble metals, ${ }^{21-28}$ and different types of ligands have been used (thiolates, ${ }^{29-33}$ phosphines, ${ }^{34-37}$ selenolates, ${ }^{38-41}$ tellurolates, ${ }^{42,43}$ acetylides, ${ }^{44-49} N$-heterocyclic carbenes ${ }^{50}$ ), thiolateprotected gold clusters still represent by far the most-studied class of MPCs. In the past decade, numerous single x-ray crystal structures containing 18 - 279 gold atoms have been reported, ${ }^{12-14,19,20,51-66}$ confirming the atomic precision and monodispersity of these 'ultrasmall gold nanoparticles'. Notably, small Au:SR clusters do not support a localized surface plasmon resonance, and their absorption spectra are dominated by discrete electronic transitions.

The electronic structure of MPCs can be described with the 'superatom complex model', in which valence electrons from the metal form delocalized orbitals that span over the volume of the cluster core. The $\left[\mathrm{Au}_{25}(\mathrm{SR})_{18}\right]^{-}$cluster is by far the most-investigated $\mathrm{Au}: S R$ cluster. ${ }^{67}$ Its atomic structure was first experimentally determined by Murray and co-workers (SR: $\left.\mathrm{SCH}_{2} \mathrm{CH}_{2} \mathrm{Ph}\right),{ }^{13}$ confirming a predicted structure. ${ }^{68}$ The cluster is composed of an icosahedral $\mathrm{Au}_{13}$ core that is protected by six SR-Au-SR-Au-SR units in octahedral arrangement, yielding a centrosymmetric structure. Small distortions in the protecting units were ascribed to the bulky counterion (tetraoctylammonium) in the crystal. The neutral species, $\mathrm{Au}_{25}(\mathrm{SR})_{18}$, does not show this distortion. ${ }^{69}$ Recently, Ackerson et al. showed that the cationic cluster, $\left[\mathrm{Au}_{25}(\mathrm{SR})_{18}\right]^{+}$is distorted due to a JahnTeller effect. ${ }^{15}$ The basic structural features, however, are conserved in all three oxidation states. Ackerson and co-workers also reported the x-ray structure of a ligand-exchanged derivate of $\left[\mathrm{Au}_{25}(\mathrm{SR})_{18}\right]^{-70}$ Here, two $-\mathrm{SCH}_{2} \mathrm{CH}_{2} \mathrm{Ph}$ ligands are replaced by $\mathrm{SPh}-4-\mathrm{Br}$ (para-bromobenzenethiol). While the authors do not exclude selection bias during the crystallization, it is notable that the two exchanged ligands are located at opposite sites of the cluster, thus maintaining the centrosymmetry of the molecule. The electronic structure of $\left[\mathrm{Au}_{25}(\mathrm{SR})_{18}\right]^{-}$can be described as an 8-electron superatom complex with a 
superatomic electron configuration of $1 \mathrm{~S}^{2}\left|1 \mathrm{P}^{6}\right| 1 \mathrm{D}^{0}$, where the $1 \mathrm{P}$ level is triply degenerate and the highest occupied molecular orbital (HOMO). The lowest unoccupied molecular orbital is a 1D state (note that the 1D levels are non-degenerate due to the symmetry of the cluster). ${ }^{68,71} \mathrm{~A}$ theoretical analysis of the electronic structure of $\left[\mathrm{Au}_{25}\left(\mathrm{SCH}_{2} \mathrm{CH}_{2} \mathrm{Ph}\right)_{16}(\mathrm{SPh}-4-\mathrm{Br})_{2}\right]^{-}$has not been performed to date, but it is intuitive that the superatomic structure is preserved, with minor modifications due to the $\mathrm{SPh}-4-\mathrm{Br}$ ligands.

Second- and third-order nonlinear optical techniques are promising tools for deep tissue imaging, due to near-infrared excitation and very localized excitation of the contrast agent. ${ }^{72-75}$ Among these, two-photon excited fluorescence and second-harmonic generation (SHG) are the most prominent nonlinear optical (NLO) effects. ${ }^{76}$ SHG can provide information on local symmetry (and changes thereof), rendering it an interesting method for biological imaging. SHG is a frequency-doubling process in which two photons of given frequency $\omega$ are annihilated during interaction with matter and one photon of doubled frequency $2 \omega$ is generated. SHG is a coherent, macroscopic phenomenon. At the molecular level, the analogous process is called Hyper-Rayleigh Scattering (HRS), which can be measured in solution. ${ }^{77,78}$ The efficiency of the process is largely dictated by the molecular first hyperpolarizability $\beta$, a rank-three tensor with 27 components. Even-order NLO processes are symmetry-sensitive, i.e. for each possible point group, a varying number of tensor components is (in)dependent and/or (non)zero. As a rule of thumb, all 27 components are zero in centrosymmetric molecules, thus evenorder NLO processes are not allowed in these.

The investigation of NLO properties of MPCs is still in its infancy, and only a few reports on the experimental determination of the first hyperpolarizabilities exist. ${ }^{79-84}$ MPCs have been proposed as multimodal imaging agents for deep tissue multiphoton microscopy applications. ${ }^{85,86}$ This requires careful selection of stable clusters that have large first hyperpolarizabilities for improved contrast in the SHG channel and large twophoton absorption cross-sections in combination with large fluorescence quantum yields for improved contrast in the fluorescence emission channel. Since the properties of MPCs do not scale, this requires rigorous experimental screening of stable clusters. Besides this application-driven need for characterization, NLO techniques are also of interest from a 
fundamental point of view, as they might be useful in the determination of electronic structure and the elucidation of the transition from molecular to collective behavior. ${ }^{84}$ This includes studying the effect of the protecting ligand. When restricting ourselves to thiolate-protected gold clusters, we can discriminate between aliphatic and aromatic thiolates, such as 2-phenylethanethiol or hexanethiol, and thiophenol or paramercaptobenzoic acid, respectively.

Noteworthy, surprisingly little attention has been paid to the effect of the ligand on the electronic structure of the MPCs. ${ }^{87-89}$ It is generally accepted that alkylthiolates such as 2-phenylethanethiol can be approximated by methylthiolate $\left(\mathrm{SCH}_{3}\right)$ or even $\mathrm{SH}$ in order to speed up DFT calculations. Regarding the first hyperpolarizability, however, we noticed that substitution of $\mathrm{SH}$ model ligands by the more realistic $\mathrm{SCH}_{3}$ already leads to a drastic change in the first hyperpolarizability. ${ }^{80}$ In phosphine-protected gold clusters, a change from $\mathrm{PRH}_{2}$ to $\mathrm{PRPh}_{3}$ also leads to a significant change of $\beta_{\text {HRS. }}{ }^{81}$ This indicates that second-order nonlinear optical properties might be very sensitive to slight changes in the electronic demand of the ligands. Due to the conjugated systems, changes in substituents of thiophenol derivatives are expected to show a very pronounced effect. For instance, Murray and co-workers showed that the ligand exchange reaction between $\left[\mathrm{Au}_{25}\left(\mathrm{SCH}_{2} \mathrm{CH}_{2} \mathrm{Ph}\right)_{18}\right]^{0 /-1}$ clusters and thiophenol, 4-bromo-thiophenol and selenophenol as incoming ligands is accelerated for the latter two. ${ }^{40}$ This was related to the $p K_{a}$ of the $\mathrm{SH} / \mathrm{SeH}$ groups. While it was initially thought that certain clusters that are stable with aliphatic thiolates are not stable when protected with aromatic ones (such as $\left[\mathrm{Au}_{25}(\mathrm{SR})_{18}\right]^{-}$ and $\mathrm{Au}_{38}(\mathrm{SR})_{24}$ which undergo core size conversion ${ }^{51,52,90,91}$ ), it was recently shown that $\mathrm{Au}_{38}(\mathrm{SPh})_{24}$ clusters can indeed be isolated. ${ }^{92}$

The centrosymmetry of the $\left[\mathrm{Au}_{25}(\mathrm{SR})_{18}\right]^{-}$(SR: achiral thiolate) cluster renders the compound inactive in second-order nonlinear optical scattering. This was confirmed both experimentally (SHG and HRS) (0,85 $^{8}$ and by DFT calculations ${ }^{93}$ of the static first hyperpolarizability $\beta_{0}$. The centrosymmetry of the $\left[\mathrm{Au}_{25}(\mathrm{SR})_{18}\right]^{-}$cluster can be broken by either protecting the cluster with chiral ligands, or by isoelectronic substitution of a few gold atoms by silver. ${ }^{80}$ Here, a new strategy for symmetry breaking in the $\left[\mathrm{Au}_{25}(\mathrm{SR})_{18}\right]^{-}$ cluster is explored using DFT calculations. We chose to study the mono-substituted $\left[\mathrm{Au}_{25}\left(\mathrm{SCH}_{3}\right)_{17}(\mathrm{SR})_{1}\right]^{-}$model system, in which one ligand is replaced by aromatic thiolate 
ligands. The symmetry-breaking in $\left[\mathrm{Au}_{25}(\mathrm{SR})_{18}\right]^{-}$clusters due to ligand exchange was suggested earlier. ${ }^{93-95}$ We present a systematic screening of the para-substituent in thiophenol derivatives by means of DFT calculations, proposing a new approach toward designing nonlinear optical responses of MPCs.

\section{Methods}

Initial guesses for structure optimization were based on the coordinates extracted from the crystal structure of $\left[\mathrm{Au}_{25}\left(\mathrm{SCH}_{2} \mathrm{CH}_{2} \mathrm{Ph}\right)_{16}(\mathrm{SPh}-4-\mathrm{Br})_{2}\right]^{-}$(I) published by Ni et al. ${ }^{70}$ From these coordinates, two model structures were generated, $\left[\mathrm{Au}_{25}\left(\mathrm{SCH}_{3}\right)_{17}(\mathrm{SPh})_{1}\right]^{-}$and $\left[\mathrm{Au}_{25}\left(\mathrm{SCH}_{3}\right)_{16}(\mathrm{SPh})_{2}\right]^{-}$. The structures were optimized and all subsequent initial guesses are based on these. All calculations were carried out using the ADF2016 software package. ${ }^{96}$ All structures were optimized at the X $\alpha /$ TZP level of theory with medium frozen cores and scalar-relativistic correction (ZORA). The static first hyperpolarizabilities were calculated at the LB94/TZ2P level of theory. The obtained tensor components were orientationally averaged to yield $\beta_{0, H R S}$, the quantity that can be determined experimentally. Details on the method can be found in ref. 93. Linear absorption spectra were calculated at the LB94/TZ2P level, considering the 50 lowest singlet-singlet transitions. The obtained transitions were broadened with Gaussians $(0.13$ eV FWHM).

\section{Results and Discussion}

Recently, Ackerson et al. reported the crystal structure of $\mathbf{I} .^{70}$ In this cluster, the two SPh4-Br ligands are found at the 'core' site of the SR-Au-SR-Au-SR protecting units (Figure 1). The two ligands occupy opposite binding sites in the cluster; this leads to maintained centrosymmetry. Note that Ackerson et al. acknowledge that selection bias during the crystallization may have occurred. 

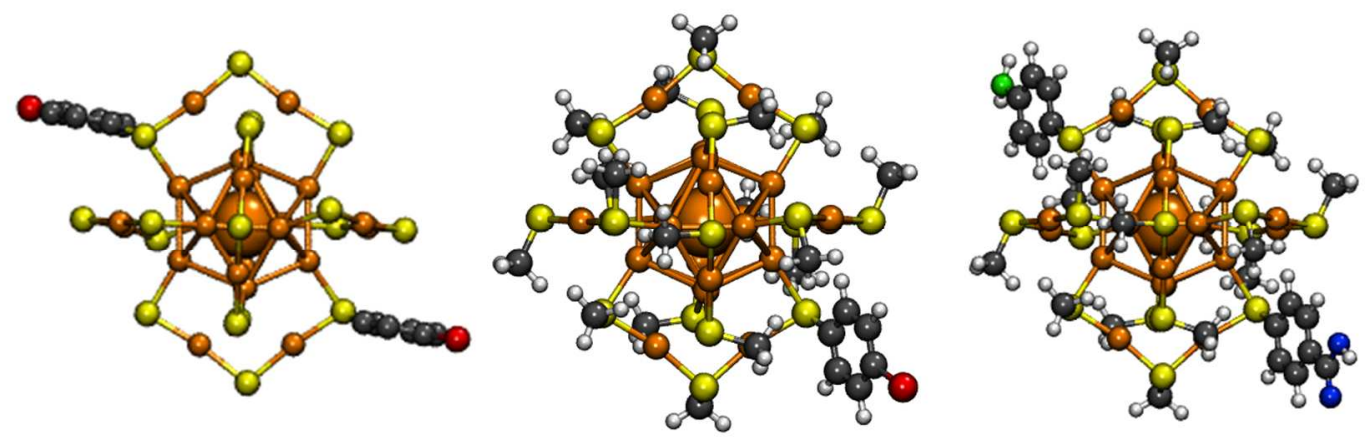

Figure 1. Left: $\mathrm{X}$-ray crystal structure of $\left[\mathrm{Au}_{25}\left(\mathrm{SCH}_{2} \mathrm{CH}_{2} \mathrm{Ph}\right)_{16}(\mathrm{SPh}-4-\mathrm{Br})_{2}\right]^{-}$, compound $\mathbf{I}$, (coordinates obtained from ref. 70), the $-\mathrm{CH}_{2} \mathrm{CH}_{2} \mathrm{Ph}$ groups and hydrogen atoms were removed for clarity. Middle: Optimized structure of $\left[\mathrm{Au}_{25}\left(\mathrm{SCH}_{3}\right)_{17}(\mathrm{SPh}-4-\mathrm{Br})_{1}\right]^{-}$(compound 7, see text). Right: Optimized structure of $\left[\mathrm{Au}_{25}\left(\mathrm{SCH}_{3}\right)_{16}(\mathrm{SPh}-4-\mathrm{COOH})_{1}\left(\mathrm{SPH}-4-\mathrm{NH}_{2}\right)_{1}\right]^{-}$(compound 16, see text). $\mathrm{Au}$, orange; sulfur, yellow; carbon, gray; hydrogen, white; bromine, red; oxygen, blue; nitrogen, green. The central atom in all clusters is shown as a large sphere.

We begin our discussion with an analysis of the electronic structure of a direct model system of Ackerson's experimental structure. For this, we chose $\left[\mathrm{Au}_{25}\left(\mathrm{SCH}_{3}\right)_{16}(\mathrm{SPh}-4-\right.$ $\left.\mathrm{H})_{2}\right]^{-}$(II). The structure was generated from the crystal structure of $\mathbf{I}$, and optimized at the $\mathrm{X} \alpha / \mathrm{TZP}$ level of theory. The electronic structure was then calculated in a single point calculation using the LB94/TZ2P formalism. Since the thiophenolate ligands are at opposite ends of the cluster, centrosymmetry is maintained, leading to a first hyperpolarizability of zero (deviations from the expected value are ascribed to either slight distortions in the structure or numerical errors arising from the calculations). The HOMO-LUMO gap of II is $1.28 \mathrm{eV}$, slightly smaller than of the all-aliphatic $\left[\mathrm{Au}_{25}\left(\mathrm{SCH}_{3}\right)_{18}\right]^{-}$(1) with a HL gap of $1.349 \mathrm{eV}$. A single thiophenolate ligand, leading to $\left[\mathrm{Au}_{25}\left(\mathrm{SCH}_{3}\right)_{17}(\mathrm{SPH}-4-\mathrm{H})_{1}\right]^{-}$(2) leads to a HL gap of $1.321 \mathrm{eV}$. Thus, with increasing number of aromatic thiolates, the HL-gap of the $\mathrm{Au}_{25}$ cluster decreases (see first entries in Tables 1 and 3; Tlahuice-Flores et al. report a $\mathrm{HL}$ gap of $1.16 \mathrm{eV}$ for $\left[\mathrm{Au}_{25}(\mathrm{SPh})_{18}\right]^{-88}$ although this value was obtained using a different code and level of theory. In earlier calculations where the electron withdrawing ligand was approximated as $\mathrm{SCH}_{2} \mathrm{Cl}$, a constant HL gap was found as the number of electron-withdrawing ligands was increased $\left.^{97}\right)$. This likely explains why all-aromatic $\left[\mathrm{Au}_{25}(\mathrm{SR})_{18}\right]^{-}$clusters are usually not stable in comparison with aliphatic ligands and undergo core size conversion. ${ }^{52}$ The 
computed linear absorption spectra show that the transitions are red-shifted when substituting the $-\mathrm{SCH}_{3}$ ligands by thiophenolate (Figure 2). Furthermore, the ligand exchange leads to level splitting, due to the lowered molecular symmetry. The red-shifted features are in good agreement with a recent report on $\mathrm{Au}_{38}(\mathrm{SPh})_{24}$ clusters, in which the optical spectrum also shows a red-shift of the key absorption features when compared to $\mathrm{Au}_{38}\left(\mathrm{SCH}_{2} \mathrm{CH}_{2} \mathrm{Ph}\right)_{24} \cdot{ }^{92}$

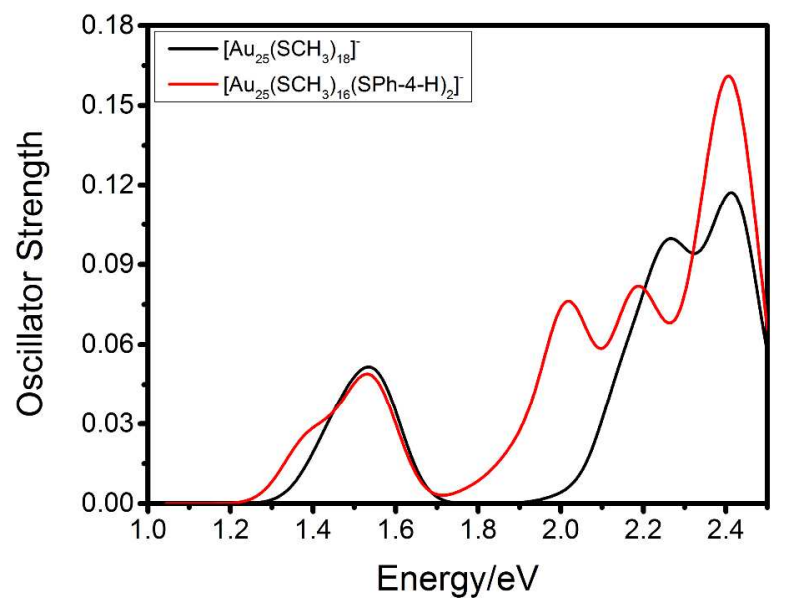

Figure 2. Calculated absorption spectra of $\left[\mathrm{Au}_{25}\left(\mathrm{SCH}_{3}\right)_{18}\right]^{-}$(compound 1, black trace) and $\left[\mathrm{Au}_{25}\left(\mathrm{SCH}_{3}\right)_{16}(\mathrm{SPh}-4-\mathrm{H})_{2}\right]^{-}$(compound II, red trace). Upon substitution of two $-\mathrm{SCH}_{3}$ ligands by $\mathrm{SPh}$, a red-shift in the transitions is observed. Furthermore, the feature at $1.5 \mathrm{eV}$ is split into two signals, likely due to non-degeneracies arising from the lowered symmetry. A new feature at ca. $2.0 \mathrm{eV}$ emerges as well.

Effect of the Ligand Structure. A series of model structures with only one aromatic ligand was constructed (the ligands are shown in Scheme 1). The substituent in the paraposition was varied to investigate its influence on the (nonlinear) optical properties of the cluster. A range of typical substituents in para-position to the sulfhydryl group was considered (compounds 2 - 11, Table 1). The structures were relaxed at the X $\alpha / T Z P$ level. The static first hyperpolarizability $\beta_{0, H R S}$ was then calculated at the LB94/TZ2P level of theory. This method was used in earlier DFT calculations of the first hyperpolarizability of thiolate-protected gold clusters. ${ }^{80,93}$ For comparison, the $\left[\mathrm{Au}_{25}\left(\mathrm{SCH}_{3}\right)_{18}\right]^{-}$cluster was also considered in the calculations. This cluster is 
centrosymmetric and its first hyperpolarizability is zero. All other structures bearing one aromatic ligand have a non-zero static first hyperpolarizability.

Scheme 1. Structures of the ten para-substituted thiophenols considered in this work. Top row, left to right: thiophenol, 4-methylthiophenol, 4-tert-butylthiophenol; 4-amino-thiophenol, 4hydroxy-thiophenol; bottom row: 4-bromo-thiophenol, 4-trifluoromethyl-thiophenol, 4mercaptobenzoic acid, 4-mercaptobenzaldehyde, 4-nitro-thiophenol.
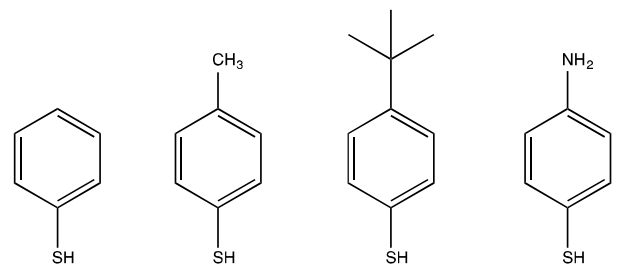<smiles>Oc1ccc(Br)cc1</smiles>
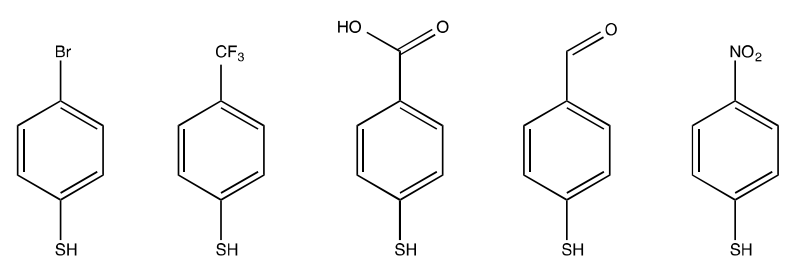

The obtained values for $\beta_{0, H R S}$ can be grouped into two classes. One set of substituents (X $\left.=\mathrm{H}, \mathrm{CH}_{3},{ }^{\mathrm{t}} \mathrm{Bu}, \mathrm{NH}_{2}, \mathrm{OH}, \mathrm{Br}, 2-7\right)$ leads to first hyperpolarizabilities of ca. $4-20 * 10^{-30}$ esu. The other set of substituents, $\mathrm{X}=\mathrm{CO}_{2} \mathrm{H}, \mathrm{CHO}$ and $\mathrm{NO}_{2}(\mathbf{9}$ - 11), yields static first hyperpolarizabilities of ca. $160-220 * 10^{-30}$ esu. This gap is likely related to the electron accepting/withdrawing properties of the substituent. The substituents in the first group are electron-donating groups (EDG), and the substituents in the second groups are electronwithdrawing groups (EWG). The first group can be further categorized into substituents with positive inductive effect $\left(+\mathrm{I}:{ }^{\mathrm{t}} \mathrm{Bu}>\mathrm{CH}_{3}>\mathrm{H}\right)$ and positive mesomeric effect $(+\mathrm{M}$ : $\left.\mathrm{NH}_{2}>\mathrm{OH}>\mathrm{Br}\right)$. The EWG substituents all have a negative mesomeric effect (-M: $\mathrm{NO}_{2}$ $>\mathrm{CHO}>\mathrm{COOH}$ ). The HOMO-LUMO gaps of the two groups are also clearly different: In the electron donating group of substituents, it is close to $1.32 \mathrm{eV}$ (and only slightly smaller than in $\left.\left[\mathrm{Au}_{25}\left(\mathrm{SCH}_{3}\right)_{18}\right]^{-}\right)$and in the electron-withdrawing group it is significantly lower $(<1 \mathrm{eV})$. In-between these groups, $\mathrm{X}=\mathrm{CF}_{3}(\mathbf{8})$ as the only pure $-\mathrm{I}$-substituent we tested is found. No more intricate correlation between the HOMO-LUMO gap and first hyperpolarizability is found. 
Table 1. HOMO-LUMO gaps (LB94/TZP) of optimized $\left[\mathrm{Au}_{25}\left(\mathrm{SCH}_{3}\right)_{17}(\mathrm{SPh}-4-\mathrm{X})_{1}\right]^{-}$clusters (X $\alpha / \mathrm{TZP})$, and their static first hyperpolarizability $\beta_{0, H R S}(\mathrm{LB} 94 / \mathrm{TZ2P})$.

\begin{tabular}{|c|c|c|c|c|}
\hline Ligand & HL-gap/eV & $\boldsymbol{\beta}_{\mathbf{0}, \mathbf{H R S}} \mathbf{1 1 0}^{-\mathbf{3 0}}$ esu & Substituent type & Compound No. \\
\hline $\mathrm{CH}_{3}$ & 1.349 & 0.009 & - & $\mathbf{1}$ \\
\hline $\mathrm{Ph}-4-\mathrm{H}$ & 1.321 & 14.4 & EDG/+I & $\mathbf{2}$ \\
\hline $\mathrm{Ph}-4-\mathrm{CH}_{3}$ & 1.323 & 16.2 & EDG/+I & $\mathbf{3}$ \\
\hline $\mathrm{Ph}-4-\mathrm{Bu}$ & 1.324 & 19.1 & EDG/+I & $\mathbf{4}$ \\
\hline $\mathrm{Ph}-4-\mathrm{NH}_{2}$ & 1.325 & 4.1 & EDG/+M & $\mathbf{5}$ \\
\hline $\mathrm{Ph}-4-\mathrm{OH}$ & 1.324 & 9.1 & EDG/+M & $\mathbf{6}$ \\
\hline $\mathrm{Ph}-4-\mathrm{Br}$ & 1.323 & 21.2 & EDG/+M & $\mathbf{7}$ \\
\hline $\mathrm{Ph}-4-\mathrm{CF}_{3}$ & 1.245 & 53.3 & EWG/-I & $\mathbf{8}$ \\
\hline $\mathrm{Ph}-4-\mathrm{CO}_{2} \mathrm{H}$ & 0.874 & 219.8 & EWG/-M & $\mathbf{9}$ \\
\hline $\mathrm{Ph}-4-\mathrm{CHO}$ & 0.726 & 212.3 & EWG/-M & $\mathbf{1 0}$ \\
\hline $\mathrm{Ph}-4-\mathrm{NO}_{2}$ & 0.344 & 157.6 & EWG/-M & $\mathbf{1 1}$ \\
\hline
\end{tabular}

It is clear from the values in Table 1 (for a plot, see Figure 3, left) that EWG substituents lead to significantly larger first hyperpolarizabilities in the $\left[\mathrm{Au}_{25}\left(\mathrm{SCH}_{3}\right)_{17}(\mathrm{SPh}-4-\mathrm{X})_{1}\right]^{-}$ clusters. We mainly relate the arising first hyperpolarizability of the clusters with EDG substituents to symmetry breaking due to the heterogeneous ligand layer. Further inspection of the trends in the $+I$ substituents (compounds 2, 3 and 4) shows a good correlation between the strength of the positive inductive effect and the first hyperpolarizability. In other words, increasing the electron density in the aromatic ring leads to larger first hyperpolarizability.

The three + M-substituents studied here $\left(\mathrm{NH}_{2}, \mathrm{OH}\right.$ and $\mathrm{Br}$; compounds 5, 6 and 7) scale as follows: with increasing $+\mathrm{M}$ effects $\left(\mathrm{NH}_{2}>\mathrm{OH}>\mathrm{Br}\right)$, the first hyperpolarizability drops. In other words, increasing the electron density in the aromatic systems does not increase the first hyperpolarizability in these systems. This is in contrast to the ligands that merely show a $+\mathrm{I}$ effect. In clusters with $-\mathrm{M}$-substituents (compounds 9, 10 and 11), the hyperpolarizability scales inversely with the strength of the $-\mathrm{M}$ effect $\left(\mathrm{NO}_{2}>\mathrm{CHO}>\right.$ $\mathrm{COOH})$, i.e. the stronger the electron acceptor, the lower the first hyperpolarizability. $\mathrm{X}=$ $\mathrm{CF}_{3}$ (8) fits into this general trend, being a weak EWG substituent. Overall, however, it might be difficult to predict the effect of the substituent based on considering inductive 
and mesomeric effects alone. As a general rule of thumb, the combination of cluster and aromatic ligand appears to be advantageous to optimize $\beta_{0, H R S}$ : we considered a free ligand, HS-Ph-NO $\mathrm{NO}_{2}\left(\beta_{0, H R S}=12 * 10^{-30} \mathrm{esu}\right)$, combining this ligand with the cluster leads to more than 10-fold increase of the first hyperpolarizability.
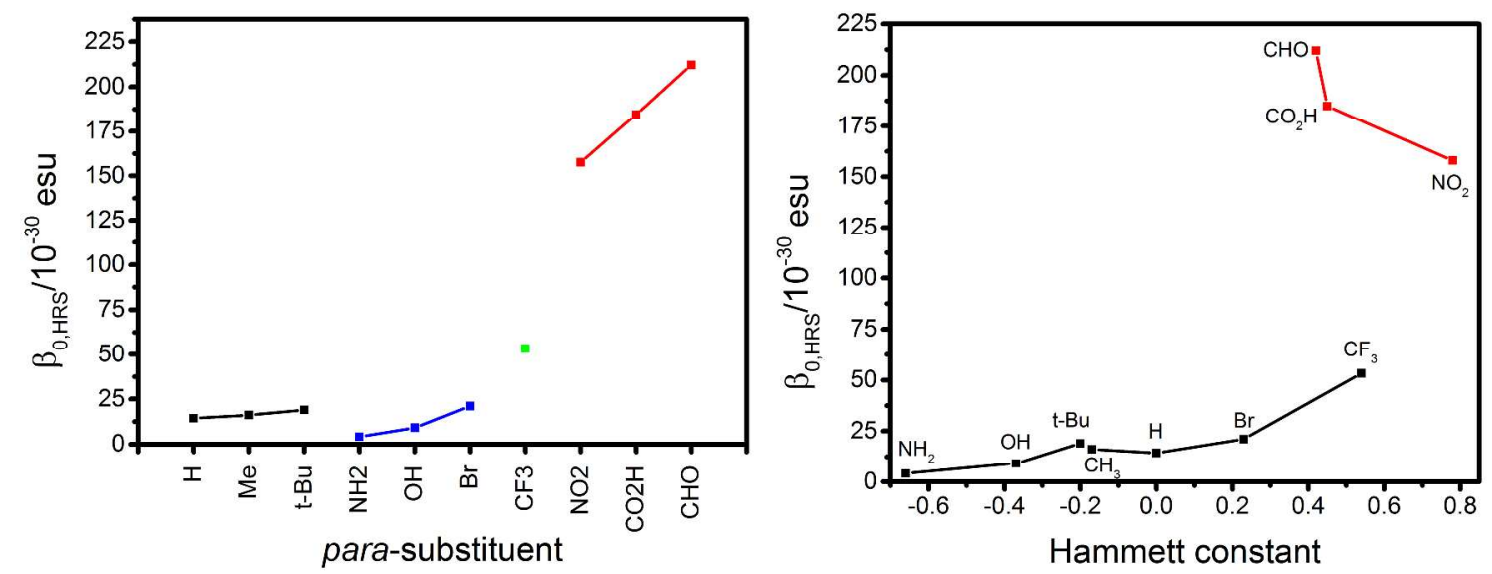

Figure 3. Left: Calculated static first hyperpolarizabilities of $\left[\mathrm{Au}_{25}\left(\mathrm{SCH}_{3}\right)_{17}(\mathrm{SPh}-4-\mathrm{X})_{1}\right]^{-}$model clusters. The substituents can be grouped into electron donating groups with + I-effect (black) and + M-effect (blue), and electron withdrawing groups (-I-effect, green; -M-effect, red). Right: Calculated static first hyperpolarizabilities of $\left[\mathrm{Au}_{25}\left(\mathrm{SCH}_{3}\right)_{17}(\mathrm{SPh}-4-\mathrm{X})_{1}\right]^{-}$model clusters, plotted against the Hammett constants of the substituents. EDG substituents and $\mathrm{X}=\mathrm{CF}_{3}(-\mathrm{I})$ are shown in black, EWG substituents (-M) in red.

In order to quantify the effect of the substituents on the first hyperpolarizability, we compared the Hammett constants $\sigma_{p}$ of the substituents ${ }^{98}$ with the calculated hyperpolarizabilities. A fair linear correlation is observed for the $+\mathrm{I}-$, $+\mathrm{M}-$ and $-\mathrm{I}-$ substituents, with increasing Hammett constant, a larger value is obtained (Figure 3, right). $\mathrm{X}=\mathrm{CF}_{3}$, albeit being a -I-substituent, fits well into this trend. The $-\mathrm{M}$ substituents scale inversely, as the Hammett constant increases, the hyperpolarizability drops. This indicates that the Hammett constant might serve as a 'ruler' to predict and quantify the effect of substituents on (nonlinear) optical properties of thiolate-protected gold clusters, when aromatic thiolates are present. A quasi-linear correlation between the Hammett constant and first hyperpolarizability has been observed over a broad range of 
substituents in purely organic chromophores; ${ }^{99}$ in the present case, the hyperpolarizability first increases with the Hammett constant, and but drops if the substituent is of the $-\mathrm{M}$ type. We assume that, depending on the ligand, the cluster acts as either electron acceptor or electron donor.

Apart from the electronic properties of the substituents, one might consider structural parameters. One of these could be the distortion of the icosahedral $\mathrm{Au}_{13}$ core using continuous symmetry measures. ${ }^{100,101}$ However, no correlation between the distortion of the icosahedron and the first hyperpolarizability was observed (data not shown here). Thus, geometric structural effects do not affect the first hyperpolarizability in a predictable way, at least for the systems considered here.

MPCs as pH sensors. Based on the Hammett substituent constants, one would expect a massive increase in the first hyperpolarizability between 4-dimethylaminothiophenol $\left(\sigma_{p}\left(\mathrm{~N}\left(\mathrm{CH}_{3}\right)_{2}\right)=-0.83\right)$ upon methylation $\left(\sigma_{p}\left(\mathrm{~N}\left(\mathrm{CH}_{3}\right)_{3}{ }^{+}\right)=+0.82\right)$. This is understood when considering that the $\mathrm{N}\left(\mathrm{CH}_{3}\right)_{2}$ substituent can provide an electron pair and is a donor substituent. The methylated (or protonated) form is electron-deficient and therefore an acceptor. Similar behavior is expected for the $\mathrm{NH}_{2} / \mathrm{NH}_{3}{ }^{+}$pair $\left(\sigma_{p}\left(\mathrm{NH}_{2}\right)=-0.66 ; \sigma_{p}\left(\mathrm{NH}_{3}{ }^{+}\right)\right.$ $=0.60)$, and the marked difference between the first hyperpolarizabilities would render such system an excellent nonlinear optical proton sensor; this could be exploited in local $\mathrm{pH}$ measurements in multiphoton microscopy applications. By extension of this argument, de-protonation of carboxyl-groups might lead to similar results. ${ }^{102}$ The dependence of HRS and SHG responses on the protonation state of the NLO chromophore has been described for small molecules, fullerenes and proteins. ${ }^{99,103-107}$ The calculated first hyperpolarizabilities of $\left[\mathrm{Au}_{25}\left(\mathrm{SCH}_{3}\right)_{17}\left(\mathrm{SPh}-4-\mathrm{NH}_{3}\right)_{1}\right]$ (12), $\left[\mathrm{Au}_{25}\left(\mathrm{SCH}_{3}\right)_{17}\left(\mathrm{SPh}-4-\mathrm{N}\left(\mathrm{CH}_{3}\right)_{2}\right)_{1}\right]^{-} \quad(\mathbf{1 3}), \quad\left[\mathrm{Au}_{25}\left(\mathrm{SCH}_{3}\right)_{17}\left(\mathrm{SPh}-4-\mathrm{N}\left(\mathrm{CH}_{3}\right)_{3}\right)_{1}\right] \quad$ (14), and $\left[\mathrm{Au}_{25}\left(\mathrm{SCH}_{3}\right)_{17}\left(\mathrm{SPh}-4-\mathrm{N}\left(\mathrm{CH}_{3}\right)_{2} \mathrm{H}\right)_{1}\right](\mathbf{1 5})$ are listed in Table 2.

We define the contrast $C$ for $\mathrm{pH}$ sensing with NLO chromophores as the squared ratio of $\beta_{0, H R S}$ of the protonated and the deprotonated forms. The square is justified since both HRS and SHG measure the square of the first hyperpolarizability and nonlinear susceptibility, respectively, in the experiment. For the clusters with one $p$ aminothiophenol ligand (5) and its protonated form (12), we find $C=88$. To our knowledge, the largest contrast to date was reported by Mancois et al. with $C=675$. $^{99}$ It 
Table 2. Optimized structures of 4-aminothiophenol substituted $A_{25}$ clusters, its protonated form, 4-dimethylaminothiophenol substituted $\mathrm{Au}_{25}$ clusters and its methylated and protonated

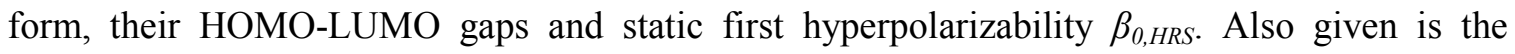
contrast between the protonated and deprotonated as well as methylated and demethylated forms, respectively.

\begin{tabular}{|c|c|c|c|c|c|}
\hline $\mathbf{X}$ & $\sigma_{p}$ & $H L-g a p / e V$ & $\beta_{0, H R S} / 10^{-30}$ esu & Compound No. & $C=\left[\left(\boldsymbol{\beta}_{\text {prot }}\right) /\left(\boldsymbol{\beta}_{\text {deprot }}\right)\right]^{2}$ \\
\hline $\mathrm{NH}_{2}$ & -0.66 & 1.325 & 4.1 & 5 & \multirow{2}{*}{88} \\
\hline$\left(\mathrm{NH}_{3}\right)^{+}$ & +0.60 & 1.14 & 38.4 & 12 & \\
\hline $\mathrm{N}\left(\mathrm{CH}_{3}\right)_{2}$ & $\begin{array}{l}-0.83 \\
\end{array}$ & 1.323 & 2.01 & 13 & \multirow{2}{*}{1742} \\
\hline$\left(\mathrm{N}\left(\mathrm{CH}_{3}\right)_{3}\right)^{+}$ & +0.82 & 0.969 & 83.9 & 14 & \\
\hline$\left(\mathrm{N}\left(\mathrm{CH}_{3}\right)_{2} \mathrm{H}\right)^{+}$ & $\mathrm{-a}^{\mathrm{a}}$ & 0.925 & 89.7 & 15 & $1992^{b}$ \\
\hline
\end{tabular}

a: unknown, but assumed to be close to +0.80 ; b: deprotonated form is compound 13 .

Push-Pull systems. A long-standing paradigm for the optimization of the first hyperpolarizability is the creation of push/pull systems. ${ }^{108}$ Following this idea, we investigated two model clusters of the form $\left[\mathrm{Au}_{25}\left(\mathrm{SCH}_{3}\right)_{16}(\mathrm{SPh}-4-\mathrm{X})_{1}\left(\mathrm{SPh}-4-\mathrm{X}^{\prime}\right)_{1}\right]^{\prime}$, where $\mathrm{X}=-\mathrm{M}$ substituent and $\mathrm{X}^{\prime}=+\mathrm{M}$ substituent. Effectively, the cluster acts as a 'conjugated linker' between donor and acceptor (Scheme 2).

The two aromatic thiolates were positioned at opposite ends of the cluster, much like the situation observed experimentally in $\left[\mathrm{Au}_{25}\left(\mathrm{SCH}_{2} \mathrm{CH}_{2} \mathrm{Ph}\right)_{16}(\mathrm{SPh}-4-\mathrm{Br})_{2}\right]^{-}$. We chose to consider $\mathrm{X}=\mathrm{CO}_{2} \mathrm{H}$ and $\mathrm{NO}_{2}$, and $\mathrm{X}^{\prime}=\mathrm{NH}_{2}$ (Table 3). For 16, little influence is found, as the first hyperpolarizability even slightly decreases when compared to $\left[\mathrm{Au}_{25}\left(\mathrm{SCH}_{3}\right)_{17}(\mathrm{SPh}-4-\mathrm{X})_{1}\right]^{-}$(specifically, compound 9 in Table 1). 
Table 3. Optimized structures of $\left[\mathrm{Au}_{25}\left(\mathrm{SCH}_{3}\right)_{16}(\mathrm{SPh}-4-\mathrm{X})_{1}\left(\mathrm{SPh}-4-\mathrm{X}^{\prime}\right)_{1}\right]^{-}$clusters, their HOMOLUMO gaps and static first hyperpolarizability $\beta_{0, H R S}$.

\begin{tabular}{|c|c|c|c|c|}
\hline $\mathbf{X}$ & $\mathbf{X}$ & HL-gap/eV & $\boldsymbol{\beta}_{\mathbf{0}, \mathbf{H R S}} / \mathbf{1 0}^{-30}$ esu & Compound No. \\
\hline $\mathrm{H}$ & $\mathrm{H}$ & 1.28 & 0.06 & $\mathbf{I I}$ \\
\hline $\mathrm{CO}_{2} \mathrm{H}$ & $\mathrm{NH}_{2}$ & 0.859 & 213.4 & $\mathbf{1 6}$ \\
\hline $\mathrm{NO}_{2}$ & $\mathrm{NH}_{2}$ & 0.089 & 284.2 & $\mathbf{1 7}$ \\
\hline
\end{tabular}

Scheme 2. Resonance between donor and acceptor ligands in compound 17. The $\mathrm{Au}_{25}$ cluster is shown as yellow sphere. For clarity, only a short protecting unit (SR-Au-SR) is shown instead of a dimeric unit as observed in $\left[\mathrm{Au}_{25}(\mathrm{SR})_{18}\right]^{-}$.

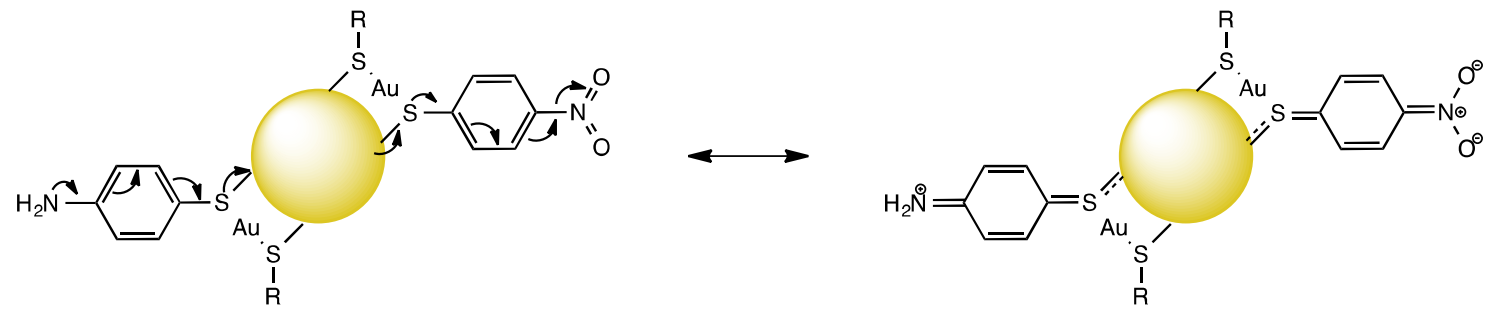

In the case of $\left(\mathrm{NO}_{2} / \mathrm{NH}_{2}\right)(17)$ a strong increase to $284.2 * 10^{-30}$ esu is calculated. This value exceeds the added values for the mono-substituted structures with $\mathrm{NO}_{2}(\mathbf{1 1})$ and $\mathrm{NH}_{2}$ (5) substituents (which would be $161.7 * 10^{-30}$ esu). This points to an effective charge transfer $(\mathrm{CT}) .{ }^{109}$ Oudar and Chemla ${ }^{110}$ defined the CT contribution $\left(\beta_{C T}\right)$ to the total hyperpolarizability $\left(\beta_{\text {total }}\right)$ as:

$$
\beta_{\text {total }}=\beta_{\text {added }}+\beta_{C T}
$$

In 17, this leads to $\beta_{C T}=122.5 * 10^{-30}$ esu. The S-C distances in the acceptor ligands are shorter than in the donor ligands, while the $\mathrm{S}-\mathrm{Au}$ (core) distances are longer than on the donor side. Furthermore, the S-C distances are shortened with respect to the monosubstituted compounds of the acceptor (9 and 11), while the S-Au(core) distances were elongated. Again, the opposite is observed when comparing the donor site to the corresponding monosubstitued cluster (5). The shortening/elongation of atom distances is more pronounced in $\mathbf{1 7}$ than in 16, suggesting that the CT-effect scales with this bond length alternation. Our results indicate that donor/acceptor systems could potentially be exploited for optimizing second-order NLO responses using thiolate-protected gold 
clusters. While the static first hyperpolarizability has not been calculated for many monolayer-protected gold clusters, ${ }^{80,81,93}$ the value computed for $\mathbf{1 7}$ is the largest thus far. The HOMO of 17 shows the superatomic character of the cluster (1P), but also extends into the functional ligands (Figure 4). The sulfur atoms of the thiophenolate ligands act as bridges between the delocalized superatomic electronic structure of the cluster itself and the phenyl rings, i.e. the delocalized system is effectively extended into the ligands. The LUMO shows only minor superatomic character, and is largely located on the - $\mathrm{Ph}-4$ $\mathrm{NO}_{2}$ substituent, and the LUMO+1 is one of the superatomic $\mathrm{D}$ states. This explains the very small HOMO-LUMO (HL) gap of this cluster $(0.089 \mathrm{eV})$. The superatomic energy gap between 1P (HOMO) and 1D (LUMO+1) is $1.239 \mathrm{eV}$, and largely unaffected by the ligand substitution. Therefore, the optical spectrum of $\mathbf{1 7}$ should show an additional transition at low energies (Figure 5), in contrast to $\left[\mathrm{Au}_{25}\left(\mathrm{SCH}_{3}\right)_{18}\right]^{-}$(1) or experimental spectra.
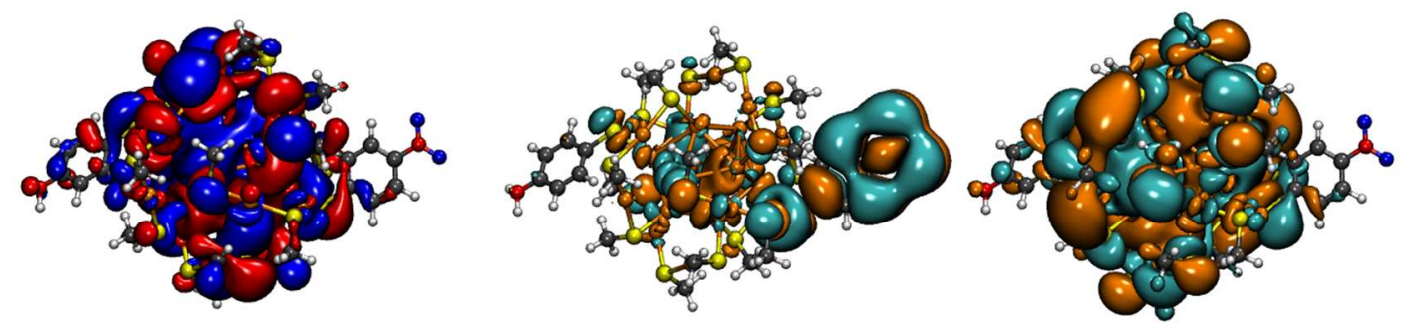

Figure 4. HOMO (left), LUMO (middle) and LUMO+1 of $\left[\mathrm{Au}_{25}\left(\mathrm{SCH}_{3}\right)_{16}\left(\mathrm{SPh}-4-\mathrm{NO}_{2}\right)_{1}(\mathrm{SPh}-4-\right.$ $\left.\left.\mathrm{NH}_{2}\right)_{1}\right]^{-}$(17) at the LB94/TZ2P level of theory (used to calculate the first hyperpolarizabilities). All structures are shown in the same orientation. The isosurface cutoff is 0.006 .

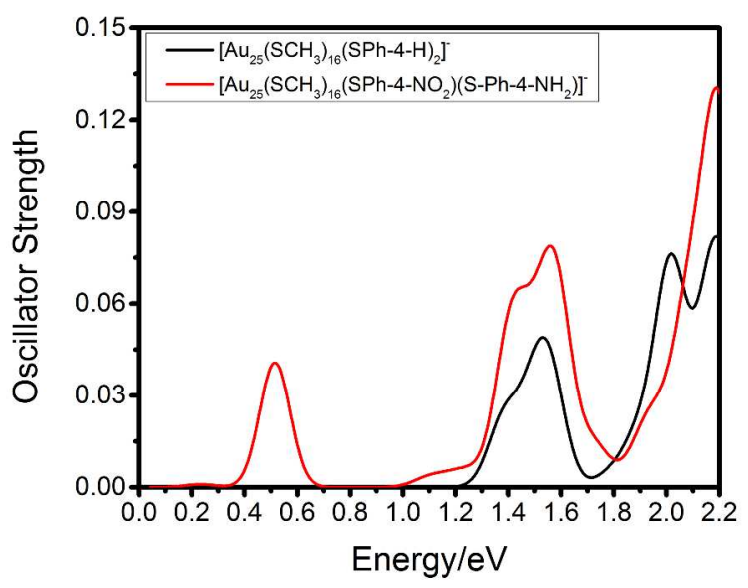


Figure 5. Calculated absorption spectra of $\left[\mathrm{Au}_{25}\left(\mathrm{SCH}_{3}\right)_{16}(\mathrm{SPH}-4-\mathrm{H})_{2}\right]^{-}$(II, black trace) and $\left[\mathrm{Au}_{25}\left(\mathrm{SCH}_{3}\right)_{16}\left(\mathrm{SPh}-4-\mathrm{NO}_{2}\right)\left(\mathrm{SPh}-4-\mathrm{NH}_{2}\right)\right]^{-}(\mathbf{1 7}$, red trace). A new feature at ca. $0.5 \mathrm{eV}$ emerges, which is due to excitation from the HOMO to the low-lying LUMO (metal-ligand charge transfer). At higher energies, the superatomic electronic structure of the cluster dominates the optical spectrum.

Intrinsic hyperpolarizabilities. Kuzyk has shown that the maximum first hyperpolarizability of a system can be expressed as:

$$
\beta_{\max }=\sqrt[3]{4}\left(\frac{e \hbar}{\sqrt{m_{e}}}\right)^{3} \frac{N^{3 / 2}}{E_{10}^{7 / 2}}
$$

where $N$ : number of electrons and $E_{10}$ : HL gap. ${ }^{111,112}$ Thus, $\beta_{\max }$ (the fundamental limit for the first hyperpolarizability) relies on a small HL gap and a large number of electrons in the cluster. The electron count $(N)$ is as follows: the superatom contributes eight electrons, the sulfur atom in the aromatic ligand contributes two electrons, each phenyl ring contributes six electrons and each donor substituent increases the count by another two electrons. With $E_{10}=E_{H L}$, we can estimate $\beta_{\max }$ for compounds 2 - 17 (Table 4). While gold is an element with strong relativistic effects, ${ }^{113,114}$ we ignore these at this point due to lack of information on how many electrons to consider in relativistic systems. ${ }^{115}$ Furthermore, thiolate-protected gold clusters would require including both non-relativistic and relativistic electron masses for the electrons, leading to additional complexity.

Table 4. Calculated maximum and intrinsic hyperpolarizabilities of compounds $\mathbf{2}-\mathbf{1 7}$ according to Kuzyk's model.

\begin{tabular}{|c|c|c|c|c|c|c|c|c|}
\hline Compound & $\mathbf{X}$ & $\mathbf{X}^{\prime}$ & $\boldsymbol{N}$ & $\boldsymbol{\beta}_{\boldsymbol{0}, \boldsymbol{H R S}} / \mathbf{1 0}^{-\mathbf{3 0}} \mathbf{e s u}$ & $\boldsymbol{E}_{10} / \mathbf{e V}$ & $\boldsymbol{\beta}_{\boldsymbol{m a x}} / \mathbf{1 0}^{\mathbf{3 0}} \mathbf{e s u}$ & $\boldsymbol{\beta}_{z z z} / \mathbf{1 0}^{-\mathbf{3 0}} \mathbf{e s u}^{\mathbf{b}}$ & $\boldsymbol{\beta}_{\text {int }}$ \\
\hline $\mathbf{2}$ & $\mathrm{H}$ & - & 16 & 14.4 & 1.321 & 2865 & 30 & 0.011 \\
\hline $\mathbf{3}$ & $\mathrm{CH}_{3}$ & - & 16 & 16.2 & 1.323 & 2850 & 37 & 0.013 \\
\hline $\mathbf{4}$ & ${ }^{\mathrm{B}}$ & - & 16 & 19.1 & 1.324 & 2842 & 44 & 0.015 \\
\hline $\mathbf{5}$ & $\mathrm{NH}_{2}$ & - & 18 & 4.1 & 1.325 & 3383 & 9 & 0.0027 \\
\hline $\mathbf{6}$ & $\mathrm{OH}$ & - & 18 & 9.1 & 1.324 & 3391 & 21 & 0.006 \\
\hline $\mathbf{7}$ & $\mathrm{Br}$ & - & 18 & 21.2 & 1.323 & 3400 & 50 & 0.015 \\
\hline $\mathbf{8}$ & $\mathrm{CF}_{3}$ & - & 16 & 53.3 & 1.245 & 3525 & 121 & 0.034 \\
\hline $\mathbf{9}$ & $\mathrm{CO}_{2} \mathrm{H}$ & - & 16 & 219.8 & 0.874 & 12161 & 413 & 0.034 \\
\hline
\end{tabular}




\begin{tabular}{|c|c|c|c|c|c|c|c|c|}
\hline $\mathbf{1 0}$ & $\mathrm{CHO}$ & - & 16 & 212.3 & 0.726 & 23280 & 477 \\
\hline $\mathbf{1 1}$ & $\mathrm{NO}_{2}$ & - & 16 & 157.6 & 0.344 & 317914 & 358 \\
\hline $\mathbf{1 2}$ & $\left(\mathrm{NH}_{3}\right)^{+}$ & - & 16 & 38.4 & 1.14 & 5726 & 0.001 \\
\hline $\mathbf{1 3}$ & $\mathrm{N}\left(\mathrm{CH}_{3}\right)_{2}$ & - & 18 & 2.01 & 1.323 & 2850 & 0.014 \\
\hline $\mathbf{1 4}$ & $\left(\mathrm{N}\left(\mathrm{CH}_{3}\right)_{3}\right)^{+}$ & - & 16 & 83.9 & 0.969 & 10113 & 0.001 \\
\hline $\mathbf{1 5}$ & $\left(\mathrm{N}\left(\mathrm{CH}_{3}\right)_{2} \mathrm{H}\right)^{+}$ & - & 16 & 89.7 & 0.925 & 9972 & 0.019 \\
\hline $\mathbf{1 6}$ & $\mathrm{CO}_{2} \mathrm{H}$ & $\mathrm{NH}_{2}$ & 26 & 213.4 & 0.859 & 26765 & 0.021 \\
\hline $\mathbf{1 7}$ & $\mathrm{NO}_{2}$ & $\mathrm{NH}_{2}$ & 26 & 284.2 & $0.5^{\mathrm{a}}$ & 177889 & 0.016 \\
\hline
\end{tabular}

a: the energy of the first transition in the optical spectrum was used instead of the HL gap. b: all $\boldsymbol{\beta}_{z z z}$ tensor components are actually negative, the absolute values are listed.

Also, an 'apparent gap' between the measured first hyperpolarizability and the maximum first hyperpolarizability was noted. ${ }^{116,117}$ The ratio of these, the intrinsic first hyperpolarizability $\beta_{\text {int }}=\beta / \beta_{\max }$, is typically close to 0.03 . Breach of this 'apparent limit' is not forbidden, and several systems were shown to have values of $\beta_{\text {int }}>0.03 .{ }^{117}$ Following convention, we use the largest tensor components $\left(\beta=\beta_{z z z}\right)$ and calculated the intrinsic hyperpolarizabilities for compounds 2 - 17. For 8 and $9\left(X=\mathrm{CF}_{3}\right.$ and $\mathrm{CHO}$, respectively), an intrinsic hyperpolarizability of 0.034 is found; these values breach the apparent limit (Figure 6). Here, the combination of a) the advantageous effect of a-I- or -M-substituent, b) a comparably small number of electrons in the system since an acceptor substituent is present and c) (for compound 9) the largest HL-gap in the three clusters with $-\mathrm{M}$-substituent that were considered here lead to the fairly large values of $\beta_{\text {int }}$. These guidelines might be taken into account for future optimization of the hyperpolarizabilities of MPCs. 

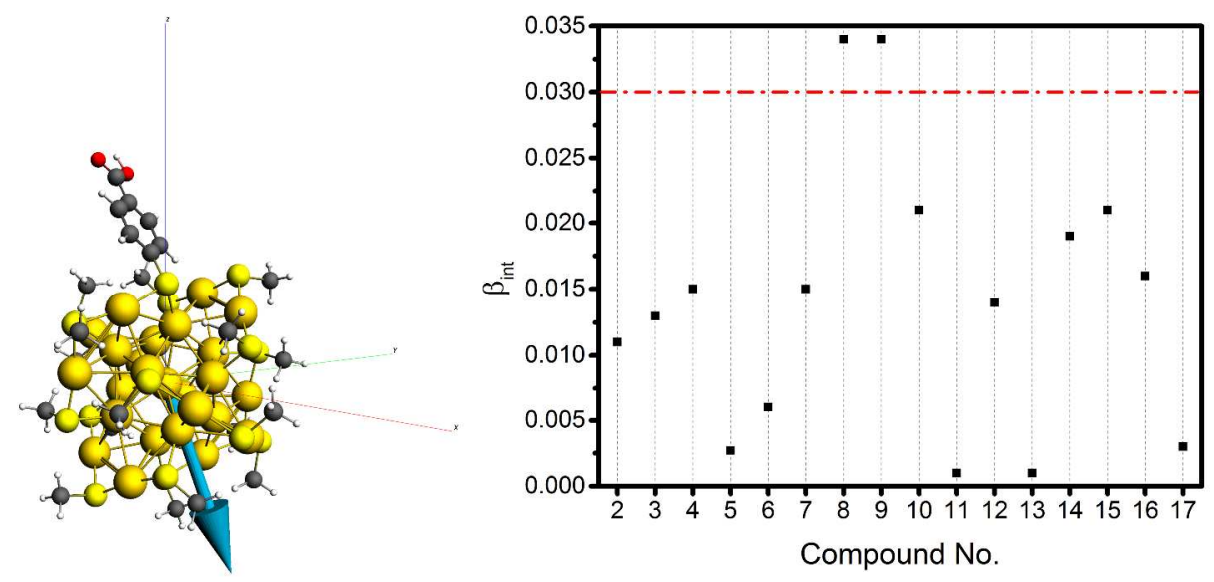

Figure 6. Left: Optimized structure of compound 9; the z-axis is shown as blue line, the dipole vector as light blue arrow. Right: Intrinsic first hyperpolarizabilities of compounds $\mathbf{2}-\mathbf{1 7}$. The red line indicates the 'apparent limit' that is frequently observed for the first hyperpolarizability.

\section{Conclusion}

In summary, we propose ligand exchange as a valuable strategy to induce significant second-order NLO effects to otherwise centrosymmetric thiolate-protected gold clusters. A series of thiophenol derivatives has been considered here, with both electron-donating and electron-withdrawing substituents in para-position relative to the thiol group. It is noteworthy that the static first hyperpolarizability can be manipulated over two orders of magnitude solely by changing the substituent. In general, electron acceptors appear to lead to larger values than electron donors. Overall, good correlation was found with the Hammett constant of the donor substituents. Protonation of amine substituents converts the donor into an acceptor substituent and this leads to a drastic increase of $\beta_{0, H R S \text {. We }}$ propose such behavior as a nonlinear proton sensor for local $\mathrm{pH}$ measurements in biological applications.

We also considered doubly substituted clusters, and introduced both acceptor and donor. The calculated hyperpolarizabilities are larger than the sum of the clusters with the individual ligands, indicating a charge transfer. The computed values presented here are stronger than those published for any other monolayer-protected gold (or gold-silver alloy) cluster so far. Finally, we analyzed the structures in terms of Kuzyk's quantum gap, and the intrinsic hyperpolarizabilities of $\mathbf{8}$ and $\mathbf{9}$ were found to breach the apparent limit of 0.03 , nevertheless falling short of the best chromophores reported thus far. While 
the ligand exchange strategy seems a valuable concept to design second-order nonlinear scatterers through symmetry-breaking and fine-tuning of the electronic properties, it remains to be seen whether or not monolayer-protected metal clusters will be suitable compounds to close the apparent gap.

\section{Supporting Information}

Coordinates of the optimized structures are provided as .xyz-files.

\section{Acknowledgement}

We gratefully acknowledge financial support from KU Leuven and the 'Funds for Scientific Research - Flanders' (FWO) through grant No. G0A1817N and a postdoctoral fellowship (S.K.). All computations were carried out at 'CSC -The IT Center for Science' (Espoo/Finland) under project number INT2605. We thank Mark G. Kuzyk (Washington State University, Pullman) for discussions on the intrinsic hyperpolarizability and fundamental limits. 


\section{References}

(1) Jin, R.; Zeng, C.; Zhou, M.; Chen, Y. Atomically Precise Colloidal Metal Nanoclusters and Nanoparticles: Fundamentals and Opportunities. Chem. Rev. 2016, 116, 10346-10413.

(2) Chakraborty, I.; Pradeep, T. Atomically Precise Clusters of Noble Metals: Emerging Link between Atoms and Nanoparticles. Chem. Rev. 2017, 117, 82088271.

(3) Ganguly, A.; Chakraborty, I.; Udayabhaskararao, T.; Pradeep, T. A Copper Cluster Protected with Phenylethanethiol. J. Nanoparticle Res. 2013, 15, 1522.

(4) Harkness, K. M.; Tang, Y.; Dass, A.; Pan, J.; Kothalawala, N.; Reddy, V. J.; Cliffel, D. E.; Demeler, B.; Stellacci, F.; Bakr, O. M.; et al. $\operatorname{Ag}_{44}(\mathrm{SR})_{30}{ }^{4-}:$ A SilverThiolate Superatom Complex. Nanoscale 2012, 4, 4269-4274.

(5) Yang, H.; Wang, Y.; Huang, H.; Gell, L.; Lehtovaara, L.; Malola, S.; Häkkinen, H.; Zheng, N. All-Thiol-Stabilized $\mathrm{Ag}_{44}$ and $\mathrm{Au}_{12} \mathrm{Ag}_{32}$ Nanoparticles with SingleCrystal Structures. Nature Commun. 2013, 4, 2422.

(6) Desireddy, A.; Conn, B. E.; Guo, J.; Yoon, B.; Barnett, R. N.; Monahan, B. M.; Kirschbaum, K.; Griffith, W. P.; Whetten, R. L.; Landman, U.; et al. Ultrastable Silver Nanoparticles. Nature 2013, 501, 399-402.

(7) Ren, L.; Yuan, P.; Su, H.-F.; Malola, S.; Lin, S.-C.; Tang, Z.; Teo, B. K.; Häkkinen, H.; Zheng, L.-S.; Zheng, N. Bulky Surface Ligands Promote Surface Reactivities of $\left[\mathrm{Ag}_{141} \mathrm{X}_{12}(\mathrm{~S}-\mathrm{Adm})_{40}\right]^{3+}(\mathrm{X}=\mathrm{Cl}, \mathrm{Br}, \mathrm{I})$ Nanoclusters: Models for Multiple-Twinned Nanoparticles. J. Am. Chem. Soc. 2017, 139, 13288-13291.

(8) Yang, H.; Wang, Y.; Chen, X.; Zhao, X.; Gu, L.; Huang, H.; Yan, J.; Xu, C.; Li, G.; Wu, J.; et al. Plasmonic Twinned Silver Nanoparticles with Molecular Precision. Nature Commun. 2016, 7, 12809.

(9) AbdulHalim, L. G.; Bootharaju, M. S.; Tang, Q.; Del Gobbo, S.; AbdulHalim, R. G.; Eddaoudi, M.; Jiang, D. E.; Bakr, O. M. $\operatorname{Ag}_{29}(\mathrm{BDT})_{12}(\mathrm{TPP})_{4}$ : A Tetravalent Nanocluster. J. Am. Chem. Soc. 2015, 137, 11970-11975.

(10) Joshi, C. P.; Bootharaju, M. S.; Alhilaly, M. J.; Bakr, O. M. $\left[\operatorname{Ag}_{25}(\mathrm{SR})_{18}\right]^{-}$: The “Golden” Silver Nanoparticle. J. Am. Chem. Soc. 2015, 137, 11578-11581.

(11) Alhilaly, M. J.; Bootharaju, M. S.; Joshi, C. P.; Besong, T. M. D.; Emwas, A.-H.; 
Juarez Mosqueda, R.; Kaappa, S.; Malola, S.; Adil, K.; Shkurenko, A.; et al. $\left[\mathrm{Ag}_{67}(\mathrm{SPhMe} 2)_{32}(\mathrm{PPh} 3)_{8}\right]^{3+}:$ Synthesis, Total Structure, and Optical Properties of a Large Box-Shaped Silver Nanocluster. J. Am. Chem. Soc. 2016, 138, 14727 14732.

(12) Jadzinsky, P. D.; Calero, G.; Ackerson, C. J.; Bushnell, D. A.; Kornberg, R. D. Structure of a Thiol Monolayer-Protected Gold Nanoparticle at 1.1 A Resolution. Science 2007, 318, 430-433.

(13) Heaven, M. W.; Dass, A.; White, P. S.; Holt, K. M.; Murray, R. W. Crystal Structure of the Gold Nanoparticle $\left[\mathrm{N}\left(\mathrm{C}_{8} \mathrm{H}_{17}\right)_{4}\right]\left[\mathrm{Au}_{25}\left(\mathrm{SCH}_{2} \mathrm{CH}_{2} \mathrm{Ph}\right)_{18}\right] . \mathrm{J} . \mathrm{Am}$. Chem. Soc. 2008, 130, 3754-3755.

(14) Qian, H.; Eckenhoff, W. T.; Zhu, Y.; Pintauer, T.; Jin, R. Total Structure Determination of Thiolate-Protected Au38 Nanoparticles. J. Am. Chem. Soc. 2010, $132,8280-8281$.

(15) Tofanelli, M. A.; Salorinne, K.; Ni, T. W.; Malola, S.; Newell, B.; Phillips, B.; Häkkinen, H.; Ackerson, C. J. Jahn-Teller Effects in $\mathrm{Au}_{25}(\mathrm{SR})_{18}$. Chem. Sci. 2016, 7, 1882-1890.

(16) Knoppe, S.; Boudon, J.; Dolamic, I.; Dass, A.; Bürgi, T. Size Exclusion Chromatography for Semipreparative Scale Separation of $\mathrm{Au}_{38}(\mathrm{SR})_{24}$ and $\mathrm{Au}_{40}(\mathrm{SR})_{24}$ and Larger Clusters. Anal. Chem. 2011, 83, 5056-5061.

(17) Knoppe, S.; Michalet, S.; Bürgi, T. Stabilization of Thiolate-Protected Gold Clusters Against Thermal Inversion: Diastereomeric $\mathrm{Au}_{38}\left(\mathrm{SCH}_{2} \mathrm{CH}_{2} \mathrm{Ph}\right)_{24-2 \mathrm{x}}(R$ BINAS)x. J. Phys. Chem. C 2013, 117, 15354-15361.

(18) Dass, A. Faradaurate Nanomolecules: A Superstable Plasmonic 76.3 kDa Cluster. J. Am. Chem. Soc. 2011, 133, 19259-19261.

(19) Zeng, C.; Chen, Y.; Kirschbaum, K.; Lambright, K. J.; Jin, R. Emergence of Hierarchical Structural Complexities in Nanoparticles and Their Assembly. Science 2016, 354, 1580-1584.

(20) Sakthivel, N. A.; Theivendran, S.; Ganeshraj, V.; Oliver, A. G.; Dass, A. Crystal Structure of Faradaurate-279: $\mathrm{Au}_{279}(\mathrm{SPh}-\mathrm{tBu})_{84}$ Plasmonic Nanocrystal Molecules. J. Am. Chem. Soc. 2017, 139, 15450 - 15459.

(21) Negishi, Y.; Igarashi, K.; Munakata, K.; Ohgake, W.; Nobusada, K. Palladium 
Doping of Magic Gold Cluster $\mathrm{Au}_{38}\left(\mathrm{SC}_{2} \mathrm{H}_{4} \mathrm{Ph}\right)_{24}$ : Formation of $\mathrm{Pd}_{2} \mathrm{Au}_{36}\left(\mathrm{SC}_{2} \mathrm{H}_{4} \mathrm{Ph}\right)_{24}$ with Higher Stability than $\mathrm{Au}_{38}\left(\mathrm{SC}_{2} \mathrm{H}_{4} \mathrm{Ph}\right)_{24}$. Chem Commun 2012, 48, 660-662.

(22) Negishi, Y.; Munakata, K.; Ohgake, W.; Nobusada, K. Effect of Copper Doping on Electronic Structure, Geometric Structure, and Stability of Thiolate-Protected $\mathrm{Au}_{25}$ Nanoclusters. J. Phys. Chem. Lett. 2012, 3, 2209-2214.

(23) Negishi, Y.; Iwai, T.; Ide, M. Continuous Modulation of Electronic Structure of Stable Thiolate-Protected $\mathrm{Au}_{25}$ Cluster by Ag Doping. Chem. Commun. 2010, 46, $4713-4715$.

(24) Kumara, C.; Aikens, C. M.; Dass, A. X-Ray Crystal Structure and Theoretical Analysis of $\mathrm{Au}_{25-x} \mathrm{Ag}_{\mathrm{x}}\left(\mathrm{SCH}_{2} \mathrm{CH}_{2} \mathrm{Ph}\right)_{18}{ }^{-}$Alloy. J. Phys. Chem. Lett. 2014, 5, 461466.

(25) Kumara, C.; Gagnon, K. J.; Dass, A. X-Ray Crystal Structure of $\mathrm{Au}_{38-}$ ${ }_{x} \mathrm{Ag}_{\mathrm{x}}\left(\mathrm{SCH}_{2} \mathrm{CH}_{2} \mathrm{Ph}\right)_{24}$ Alloy Nanomolecules. J. Phys. Chem. Lett. 2015, 6, $1223-$ 1228.

(26) Kumara Dass, A., C. (AuAg) $)_{144}(\mathrm{SR})_{60}$ Alloy Nanomolecules. Nanoscale 2011, 3, 3064-3067.

(27) Kumara, C.; Zuo, X.; Cullen, D. A.; Dass, A. $\operatorname{Au}_{329-X} \operatorname{Ag}_{X}(\mathrm{SR})_{84}$ Nanomolecules: Plasmonic Alloy Faradaurate-329. J. Phys. Chem. Lett. 2015, 6, 3320-3326.

(28) Yang, H.; Wang, Y.; Lei, J.; Shi, L.; Wu, X.; Makinen, V.; Lin, S.; Tang, Z.; He, J.; Häkkinen, H.; et al. Ligand-Stabilized $\mathrm{Au}_{13} \mathrm{Cu}_{(\mathrm{x})}(\mathrm{X}=2,4,8)$ Bimetallic Nanoclusters: Ligand Engineering to Control the Exposure of Metal Sites. J. Am. Chem. Soc. 2013, 135, 9568-9571.

(29) Brust, M.; Walker, M.; Bethell, D.; Schiffrin, D. J.; Whyman, R. Synthesis of Thiol-Derivatised Gold Nanoparticles in a Two-Phase Liquid-Liquid System. $J$. Chem. Soc. Chem. Commun. 1994, 801.

(30) Brust, M.; Fink, J.; Bethell, D.; Schiffrin, D. J.; Kiely, C. Synthesis and Reactions of Functionalised Gold Nanoparticles. J. Chem. Soc. Chem. Commun. 1995, 1655.

(31) Schaaff, T. G.; Whetten, R. L. Giant Gold-Glutathione Cluster Compounds: Intense Optical Activity in Metal-Based Transitions. J. Phys. Chem. B 2000, 104, 2630-2641. 
(32) Gautier, C.; Taras, R.; Gladiali, S.; Bürgi, T. Chiral 1,1'-binaphthyl-2,2'-dithiolStabilized Gold Clusters: Size Separation and Optical Activity in the UV-Vis. Chirality 2008, 20, 486-493.

(33) Hassinen, J.; Pulkkinen, P.; Kalenius, E.; Pradeep, T.; Tenhu, H.; Häkkinen, H.; Ras, R. H. A. Mixed-Monolayer-Protected $\mathrm{Au}_{25}$ Clusters with Bulky calix[4]arene Functionalities. J. Phys. Chem. Lett. 2014, 5, 585-589.

(34) Malatesta, L. Cluster Compounds of Gold. Gold Bull. 1975, 8, 48-52.

(35) Teo, B. K.; Zhang, H.; Shi, X. Molecular Architecture of a Novel Vertex-Sharing Biicosahedral Cluster $\left[\left(\mathrm{p}-\mathrm{Tol}_{3} \mathrm{P}\right)_{10} \mathrm{Au}_{13} \mathrm{Ag}_{12} \mathrm{Br}_{8}\right]\left(\mathrm{PF}_{6}\right)$ Containing a StaggeredStaggered-Staggered Configuration for the 25-Atom Metal Framework. Inorg. Chem. 1990, 29, 2083-2091.

(36) Yanagimoto, Y.; Negishi, Y.; Fujihara, H.; Tsukuda, T. Chiroptical Activity of BINAP-Stabilized Undecagold Clusters. J. Phys. Chem. B 2006, 110, 1161111614.

(37) Wan, X. K.; Yuan, S. F.; Lin, Z. W.; Wang, Q. M. A Chiral Gold Nanocluster au20 Protected by Tetradentate Phosphine Ligands. Angew. Chem. Intl. Ed. 2014, $53,2923-2926$.

(38) Kurashige, W.; Yamaguchi, M.; Nobusada, K.; Negishi, Y. Ligand-Induced Stability of Gold Nanoclusters: Thiolate versus Selenolate. J. Phys. Chem. Lett. 2012, 2649-2652.

(39) Song, Y.; Wang, S.; Zhang, J.; Kang, X.; Chen, S.; Li, P.; Sheng, H.; Zhu, M. Crystal Structure of Selenolate-Protected $\mathrm{Au}_{24}(\mathrm{SeR})_{20}$ Nanocluster. J. Am. Chem. Soc. 2014, 136, 2963-2965.

(40) Carducci, T. M.; Blackwell, R. E.; Murray, R. W. Charge-Transfer Effects in Ligand Exchange Reactions of $\mathrm{Au}_{25}$ Monolayer-Protected Clusters. J. Phys. Chem. Lett. 2015, 6, 1299-1302.

(41) Song, Y.; Zhong, J.; Yang, S.; Wang, S.; Cao, T.; Zhang, J.; Li, P.; Hu, D.; Pei, Y.; Zhu, M. Crystal Structure of $\mathrm{Au}_{25}(\mathrm{SePh})_{18}$ Nanoclusters and Insights into Their Electronic, Optical and Catalytic Properties. Nanoscale 2014, 6, 13977-13985.

(42) Bumbu, O.; Ceamanos, C.; Crespo, O.; Gimeno, M. C.; Laguna, A.; Silvestru, C.; Villacampa, M. D. Unprecedented Gold-Tellurolate Clusters $\left[\mathrm{Au}_{8}(\mu-\mathrm{TeR})\right.$ 
$\left.{ }_{8}\left(\mathrm{PR}_{3}^{\prime}\right)_{4}\right]$. Inorg. Chem. 2007, 46, 11457-11460.

(43) Kurashige, W.; Yamazoe, S.; Yamaguchi, M.; Nishido, K.; Nobusada, K.; Tsukuda, T.; Negishi, Y. $\mathrm{Au}_{25}$ Clusters Containing Unoxidized Tellurolates in the Ligand Shell. J. Phys. Chem. Lett. 2014, 5, 2072-2076.

(44) Maity, P.; Takano, S.; Yamazoe, S.; Wakabayashi, T.; Tsukuda, T. Binding Motif of Terminal Alkynes on Gold Clusters. J. Am. Chem. Soc. 2013, 135, 9450-9457.

(45) Wan, X.-K.; Xu, W. W.; Yuan, S.-F.; Gao, Y.; Zeng, X.-C.; Wang, Q.-M. A NearInfrared-Emissive Alkynyl-Protected $\mathrm{Au}_{24}$ Nanocluster. Angew. Chemie Intl. Ed. 2015, 54, 9683-9686.

(46) Wan, X.-K.; Yuan, S.-F.; Tang, Q.; Jiang, D.; Wang, Q.-M. Alkynyl-Protected $\mathrm{Au}_{23}$ Nanocluster: A 12-Electron System. Angew. Chemie Intl. Ed. 2015, 54, 5977-5980.

(47) Wang, Y.; Su, H.; Xu, C.; Li, G.; Gell, L.; Lin, S.; Tang, Z.; Häkkinen, H.; Zheng, N. An Intermetallic $\mathrm{Au}_{24} \mathrm{Ag}_{20}$ Superatom Nanocluster Stabilized by Labile Ligands. J. Am. Chem. Soc. 2015, 137, 4324-4327.

(48) Shen, H.; Mizuta, T. An Atomically Precise Alkynyl-Protected PtAg $\operatorname{Ag}_{42}$ Superatom Nanocluster and Its Structural Implications. Chem. - An Asian J. 2017.

(49) Wan, X.-K.; Guan, Z.-J.; Wang, Q.-M. Homoleptic Alkynyl-Protected Gold Nanoclusters: $\mathrm{Au}_{44}(\mathrm{PhC} \equiv \mathrm{C})_{28}$ and $\mathrm{Au}_{36}(\mathrm{PhC} \equiv \mathrm{C})_{24}$. Angew. Chemie 2017, 129, $11652-11655$.

(50) Salorinne, K.; Man, R. W. Y.; Li, C.-H.; Taki, M.; Nambu, M.; Crudden, C. M. Water-Soluble N-Heterocyclic Carbene-Protected Gold Nanoparticles: SizeControlled Synthesis, Stability, and Optical Properties. Angew. Chem. Intl. Ed. 2017, 56, 6198-6202.

(51) Zeng, C.; Qian, H.; Li, T.; Li, G.; Rosi, N. L.; Yoon, B.; Barnett, R. N.; Whetten, R. L.; Landman, U.; Jin, R. Total Structure and Electronic Properties of the Gold Nanocrystal $\mathrm{Au}_{36}(\mathrm{SR})_{24}$. Angew. Chem. Intl. Ed. 2012, 51, 13114-13118.

(52) Zeng, C.; Li, T.; Das, A.; Rosi, N. L.; Jin, R. Chiral Structure of Thiolate-Protected 28-Gold-Atom Nanocluster Determined by X-Ray Crystallography. J. Am. Chem. Soc. 2013, 135, 10011-10013.

(53) Crasto, D.; Malola, S.; Brosofsky, G.; Dass, A.; Häkkinen, H. Single Crystal XRD 
Structure and Theoretical Analysis of the Chiral $\mathrm{Au}_{30} \mathrm{~S}(\mathrm{~S}-\mathrm{t}-\mathrm{Bu})_{18}$ Cluster. J. Am. Chem. Soc. 2014, 136, 5000-5005.

(54)

Dass, A.; Theivendran, S.; Nimmala, P. R.; Kumara, C.; Jupally, V. R.; Fortunelli, A.; Sementa, L.; Barcaro, G.; Zuo, X.; Noll, B. C. $\mathrm{Au}_{133}(\mathrm{SPh}-\mathrm{tBu})_{52}$ Nanomolecules: X-Ray Crystallography, Optical, Electrochemical, and Theoretical Analysis. J. Am. Chem. Soc. 2015, 137, 4610-4613.

(55) Zeng, C.; Chen, Y.; Kirschbaum, K.; Appavoo, K.; Sfeir, M. Y.; Jin, R. Structural Patterns at All Scales in a Nonmetallic Chiral $\mathrm{Au}_{133}(\mathrm{SR})_{52}$ Nanoparticle. Sci. $A d v$. 2015, 1 , e1500045-e1500045.

(56)

Chen, Y.; Zeng, C.; Liu, C.; Kirschbaum, K.; Gayathri, C.; Gil, R. R.; Rosi, N. L.; Jin, R. Crystal Structure of Barrel-Shaped Chiral $\mathrm{Au}_{130}(p-\mathrm{MBT})_{50}$ Nanocluster. $J$. Am. Chem. Soc. 2015, 137, 10076-10079.

(57) Zeng, C.; Chen, Y.; Liu, C.; Nobusada, K.; Rosi, N. L.; Jin, R. Gold Tetrahedra Coil up: Kekule-like and Double Helical Superstructures. Sci. Adv. 2015, 1, e1500425-e1500425.

(58) Zeng, C.; Chen, Y.; Iida, K.; Nobusada, K.; Kirschbaum, K.; Lambright, K. J.; Jin, R. Gold Quantum Boxes: On the Periodicities and the Quantum Confinement in the $\mathrm{Au}_{28}, \mathrm{Au}_{36}, \mathrm{Au}_{44}$, and $\mathrm{Au}_{52}$ Magic Series. J. Am. Chem. Soc. 2016, 138, 39503953.

(59) Zeng, C.; Liu, C.; Chen, Y.; Rosi, N. L.; Jin, R. Atomic Structure of SelfAssembled Monolayer of Thiolates on a Tetragonal Au92 Nanocrystal. J. Am. Chem. Soc. 2016, 138, 8710-8713.

(60) Das, A.; Li, T.; Nobusada, K.; Zeng, C.; Rosi, N. L.; Jin, R. Nonsuperatomic $\left[\mathrm{Au}_{23}\left(\mathrm{SC}_{6} \mathrm{H}_{11}\right)_{16}\right]^{-}$Nanocluster Featuring Bipyramidal $\mathrm{Au}_{15}$ Kernel and Trimeric $\mathrm{Au}_{3}(\mathrm{SR})_{4}$ Motif. J. Am. Chem. Soc. 2013, 135, 18264-18267.

(61) Jones, T. C.; Sementa, L.; Stener, M.; Gagnon, K. J.; Thanthirige, V. D.; Ramakrishna, G.; Fortunelli, A.; Dass, A. $\mathrm{Au}_{21} \mathrm{~S}(\mathrm{SAdm})_{15}$ : Crystal Structure, Mass Spectrometry, Optical Spectroscopy, and First-Principles Theoretical Analysis. $J$. Phys. Chem. C 2017, 121, 10865-10869.

(62) Das, A.; Liu, C.; Byun, H. Y.; Nobusada, K.; Zhao, S.; Rosi, N.; Jin, R. Structure Determination of $\left[\mathrm{Au}_{18}(\mathrm{SR})_{14}\right]$. Angew. Chemie Int. Ed. 2015, 54, 3140-3144. 
(63) Chen, S.; Wang, S.; Zhong, J.; Song, Y.; Zhang, J.; Sheng, H.; Pei, Y.; Zhu, M. The Structure and Optical Properties of the $\left[\mathrm{Au}_{18}(\mathrm{SR})_{14}\right]$ Nanocluster. Angew. Chemie Int. Ed. 2015, 54, 3145-3149.

(64) Crasto, D.; Barcaro, G.; Stener, M.; Sementa, L.; Fortunelli, A.; Dass, A. $\mathrm{Au}_{24}(\mathrm{SAdm})_{16}$ Nanomolecules: X-Ray Crystal Structure, Theoretical Analysis, Adaptability of Adamantane Ligands to Form $\mathrm{Au}_{23}(\mathrm{SAdm})_{16}$ and $\mathrm{Au}_{25}(\mathrm{SAdm})_{16}$, and Its Relation to $\mathrm{Au}_{25}(\mathrm{SR})_{18} . \mathrm{J}$. Am. Chem. Soc. 2014, 136, 14933-14940.

(65) Das, A.; Li, T.; Li, G.; Nobusada, K.; Zeng, C.; Rosi, N. L.; Jin, R. Crystal Structure and Electronic Properties of a Thiolate-Protected $\mathrm{Au}_{24}$ Nanocluster. Nanoscale 2014, 6, 6458-6462.

(66) Higaki, T.; Liu, C.; Zhou, M.; Luo, T. Y.; Rosi, N. L.; Jin, R. Tailoring the Structure of 58-Electron Gold Nanoclusters: $\mathrm{Au}_{103} \mathrm{~S}_{2}(\mathrm{~S}-\mathrm{Nap})_{41}$ and Its Implications. J. Am. Chem. Soc. 2017, 139, 9994-10001.

(67) Parker, J. F.; Fields-Zinna, C. A.; Murray, R. W. The Story of a Monodisperse Gold Nanoparticle: $\mathrm{Au}_{25} \mathrm{~L}_{18}$. Acc Chem Res 2010, 43, 1289-1296.

(68) Akola Walter, M., Whetten, R. L., Häkkinen, H., Grönbeck, H., J. On the Structure of Thiolate-Protected $\mathrm{Au}_{25}$. J. Am. Chem. Soc. 2008, 130, 3756-3757.

(69) Zhu, M.; Eckenhoff, W. T.; Pintauer, T.; Jin, R. Conversion of Anionic [ $\left.\mathrm{Au}_{25}\left(\mathrm{SCH}_{2} \mathrm{CH}_{2} \mathrm{Ph}\right)_{18}\right]^{-}$Cluster to Charge Neutral Cluster via Air Oxidation. $J$. Phys. Chem. C 2008, 112, 14221-14224.

(70) Ni, T. W.; Tofanelli, M. A.; Phillips, B. D.; Ackerson, C. J. Structural Basis for Ligand Exchange on $\mathrm{Au}_{25}(\mathrm{SR})_{18}$. Inorg. Chem. 2014, 53, 6500-6502.

(71) Walter, M.; Akola, J.; Lopez-Acevedo, O.; Jadzinsky, P. D.; Calero, G.; Ackerson, C. J.; Whetten, R. L.; Grönbeck, H.; Häkkinen, H. A Unified View of LigandProtected Gold Clusters as Superatom Complexes. Proc. Natl. Acad. Sci. 2008, 105, 9157-9162.

(72) Helmchen, F.; Denk, W. Deep Tissue Two-Photon Microscopy. Nature Methods 2005, 2, 932-940.

(73) Reeve, J. E.; Collins, H. A.; De Mey, K.; Kohl, M. M.; Thorley, K. J.; Paulsen, O.; Clays, K.; Anderson, H. L. Amphiphilic Porphyrins for Second Harmonic Generation Imaging. J. Am. Chem. Soc. 2009, 131, 2758-2759. 
(74) Reeve, J. E.; Anderson, H. L.; Clays, K. Dyes for Biological Second Harmonic Generation Imaging. Phys. Chem. Chem. Phys. 2010, 12, 13484.

(75) Lopez-Duarte, I.; Reeve, J. E.; Perez-Moreno, J.; Boczarow, I.; Depotter, G.; Fleischhauer, J.; Clays, K.; Anderson, H. L. "Push-No-Pull” porphyrins for Second Harmonic Generation Imaging. Chem. Sci. 2013, 4, 2024-2027.

(76) Verbiest, T.; Clays, K.; Rodríguez, V. Second-Order Nonlinear Optical Characterization Techniques: An Introduction; 1st ed.; CRC Press.

(77) Clays, K.; Persoons, A. Hyper-Rayleigh Scattering in Solution. Phys. Rev. Lett. 1991, 66, 2980-2983.

(78) Hendrickx, E.; Clays, K.; Persoons, A. Hyper-Rayleigh Scattering in Isotropic Solution. Acc. Chem. Res. 1998, 31, 675-683.

(79) Russier-Antoine, I.; Bertorelle, F.; Vojkovic, M.; Rayane, D.; Salmon, E.; Jonin, C.; Dugourd, P.; Antoine, R.; Brevet, P.-F. Non-Linear Optical Properties of Gold Quantum Clusters. The Smaller the Better. Nanoscale 2014, 6, 13572-13578.

(80) Van Steerteghem, N.; Van Cleuvenbergen, S.; Deckers, S.; Kumara, C.; Dass, A.; Häkkinen, H.; Clays, K.; Verbiest, T.; Knoppe, S. Symmetry Breaking in LigandProtected Gold Clusters Probed by Nonlinear Optics. Nanoscale 2016, 8, 1212312127.

(81) Knoppe, S.; Zhang, Q.-F.; Wan, X.-K.; Wang, Q.-M.; Wang, L.-S.; Verbiest, T. Second-Order Nonlinear Optical Scattering Properties of Phosphine-Protected $\mathrm{Au}_{20}$ Clusters. Ind. Eng. Chem. Res. 2016, 55, 10500-10506.

(82) Russier-Antoine, I.; Bertorelle, F.; Hamouda, R.; Rayane, D.; Dugourd, P.; Sanader, Z.; Bonačić-Koutecky, V.; Brevet, P.-F.; Antoine, R. Tuning $\operatorname{Ag}_{29}$ Nanocluster Light Emission from Red to Blue with One and Two-Photon Excitation. Nanoscale 2016, 8, 2892-2898.

(83) Bertorelle, F.; Russier-Antoine, I.; Calin, N.; Comby-Zerbino, C.; Bensalah, A.; Guy, S.; Dugourd, P.; Brevet, P.-F.; Sanader, Z.; Krstic, M.; et al. Au ${ }_{10}(\mathrm{SG})_{10}$ : A Chiral Gold Catenane Nanocluster with Zero Confined Electrons - Optical Properties and First-Principles Theoretical Analysis. J. Phys. Chem. Lett. 2017, 8, 1979-1985.

(84) Knoppe, S.; Verbiest, T. Resonance Enhancement of Nonlinear Optical Scattering 
in Monolayer-Protected Gold Clusters. J. Am. Chem. Soc. 2017, 139, 1485314856.

(85) Knoppe, S.; Vanbel, M. K.; Van Cleuvenbergen, S. J.; Vanpraet, L.; Bürgi, T.; Verbiest, T. Nonlinear Optical Properties of Thiolate-Protected Gold Clusters. $J$. Phys. Chem. C 2015, 119, 6221-6226.

(86) Brach, K.; Waszkielewicz, M.; Olesiak-Banska, J.; Samoc, M.; Matczyszyn, K. Two-Photon Imaging of 3D Organization of Bimetallic AuAg Nanoclusters in DNA Matrix. Langmuir 2017, 33, 8993-8999.

(87) Jung, J.; Kang, S.; Han, Y.-K. Ligand Effects on the Stability of Thiol-Stabilized Gold Nanoclusters: $\mathrm{Au}_{25}(\mathrm{SR})_{18}{ }^{-}, \mathrm{Au}_{38}(\mathrm{SR})_{24}$, and $\mathrm{Au}_{102}(\mathrm{SR})_{44}$. Nanoscale 2012, 4 , 4206.

(88) Tlahuice-Flores, A.; Whetten, R. L.; Jose-Yacaman, M. Ligand Effects on the Structure and the Electronic Optical Properties of Anionic $\mathrm{Au}_{25}(\mathrm{SR})_{18}$ Clusters. $J$. Phys. Chem. C 2013, 117, 20867-20875.

(89) Tlahuice-Flores, A. Ligand Effects on the Optical and Chiroptical Properties of the Thiolate $\mathrm{Au}_{18}$ Cluster. Phys. Chem. Chem. Phys. 2016, 18, 27738-27744.

(90) Nimmala, P. R.; Dass, A. $\mathrm{Au}_{36}(\mathrm{Ph})_{23}$ Nanomolecules. J. Am. Chem. Soc. 2011, $133,9175-9177$.

(91) Nimmala, P. R.; Knoppe, S.; Jupally, V. R.; Delcamp, J. H.; Aikens, C. M.; Dass, A. $\mathrm{Au}_{36}(\mathrm{SPh})_{24}$ Nanomolecules: X-Ray Crystal Structure, Optical Spectroscopy, Electrochemistry, and Theoretical Analysis. J. Phys. Chem. B 2014, 118, 1415714167.

(92) Rambukwella, M.; Burrage, S.; Neubrander, M.; Baseggio, O.; Apra, E.; Stener, M.; Fortunelli, A.; Dass, A. $\mathrm{Au}_{38}(\mathrm{SPh})_{24}: \mathrm{Au}_{38}$ Protected with Aromatic Thiolate Ligands. J. Phys. Chem. Lett. 2017, 8, 1530-1537.

(93) Knoppe, S.; Häkkinen, H.; Verbiest, T. Nonlinear Optical Properties of ThiolateProtected Gold Clusters: A Theoretical Survey of the First Hyperpolarizabilities. J. Phys. Chem. C 2015, 119, 27676-27682.

(94) Knoppe, S.; Bürgi, T. The Fate of $\mathrm{Au}_{25}(\mathrm{SR})_{18}$ Clusters upon Ligand Exchange with Binaphthyl-Dithiol: Interstaple Binding vs. Decomposition. Phys. Chem. Chem. Phys. 2013, 15, 15816-15820. 
(95) Sels, A.; Barrabés, N.; Knoppe, S.; Bürgi, T. Isolation of Atomically Precise Mixed Ligand Shell $\mathrm{PdAu}_{24}$ Clusters. Nanoscale 2016, 8, 11130-11135.

(96) te Velde, G.; Bickelhaupt, F. M.; Baerends, E. J.; Fonseca Guerra, C.; van Gisbergen, S. J. A.; Snijders, J. G.; Ziegler, T. Chemistry with ADF. J. Comput. Chem. 2001, 22, 931-967.

(97) Parker, J. F.; Kacprzak, K. A.; Lopez-Acevedo, O.; Häkkinen, H.; Murray, R. W. Experimental and Density Functional Theory Analysis of Serial Introductions of Electron-Withdrawing Ligands into the Ligand Shell of a Thiolate-Protected $\mathrm{Au}_{25}$ Nanoparticle. J. Phys. Chem. C 2010, 114, 8276-8281.

(98) Hansch, C.; Leo, A.; Taft, R. W. A Survey of Hammett Substituent Constants and Resonance and Field Parameters. Chem. Rev. 1991, 91, 165-195.

(99) Mancois, F.; Pozzo, J.-L.; Pan, J.; Adamietz, F.; Rodriguez, V.; Ducasse, L.; Castet, F.; Plaquet, A.; Champagne, B. Two-Way Molecular Switches with Large Nonlinear Optical Contrast. Chem. - A Eur. J. 2009, 15, 2560-2571.

(100) Kanis, D. R.; Wong, J. S.; Marks, T. J.; Ratner, M. a.; Zabrodsky, H.; Keinan, S.; Avnir, D. Continuous Symmetry Analysis of Hyperpolarizabilities. Characterization of the Second-Order Nonlinear Optical Response of Distorted Benzene. J. Phys. Chem. 1995, 99, 11061-11066.

(101) Avnir, D. Continous Symmetry Measures http://www.csm.huji.ac.il/new/.

(102) Kneipp, J.; Kneipp, H.; Wittig, B.; Kneipp, K. One- and Two-Photon Excited Optical pH Probing for Cells Using Surface-Enhanced Raman and Hyper-Raman Nanosensors. Nano Lett. 2007, 7, 2819-2823.

(103) Asselberghs, I.; Zhao, Y.; Clays, K.; Persoons, A.; Comito, A.; Rubin, Y. Reversible Switching of Molecular Second-Order Nonlinear Optical Polarizability through Proton-Transfer. Chem. Phys. Lett. 2002, 364, 279-283.

(104) Asselberghs, I.; Hennrich, G.; Clays, K. Proton-Triggered Octopolar NLO Chromophores. J. Phys. Chem. A 2006, 110, 6271-6275.

(105) Castet, F.; Champagne, B.; Pina, F.; Rodriguez, V. A Multistate pH-Triggered Nonlinear Optical Switch. ChemPhysChem 2014, 15, 2221-2224.

(106) Cariati, E.; Dragonetti, C.; Lucenti, E.; Nisic, F.; Righetto, S.; Roberto, D.; Tordin, E. An Acido-Triggered Reversible Luminescent and Nonlinear Optical Switch 
Based on a Substituted Styrylpyridine: EFISH Measurements as an Unusual Method to Reveal a Protonation-Deprotonation NLO Contrast. Chem. Commun. 2014, 50, 1608-1610.

(107) van Bezouw, S.; Campo, J.; Lee, S.-H.; Kwon, O.-P.; Wenseleers, W. Organic Compounds with Large and High-Contrast $\mathrm{pH}-$ Switchable Nonlinear Optical Response. J. Phys. Chem. C 2015, 119, 21658-21663.

(108) Verbiest, T.; Houbrechts, S.; Kauranen, M.; Clays, K.; Persoons, A. Second-Order Nonlinear Optical Materials: Recent Advances in Chromophore Design. J. Mater. Chem. 1997, 7, 2175-2189.

(109) Levine, B. F. Donor-Acceptor Charge Transfer Contributions to the Second Order Hyperpolarizability. Chem. Phys. Lett. 1976, 37, 516-520.

(110) Oudar, J. L.; Chemla, D. S. Hyperpolarizabilities of the Nitroanilines and Their Relations to the Excited State Dipole Moment. J. Chem. Phys. 1977, 66, 26642668.

(111) Kuzyk, M. G. Physical Limits on Electronic Nonlinear Molecular Susceptibilities. Phys. Rev. Lett. 2000, 85, 1218-1221.

(112) Kuzyk, M. G.; Pérez-Moreno, J.; Shafei, S. Sum Rules and Scaling in Nonlinear Optics. Phys. Rep. 2013, 529, 297-398.

(113) Pykkö, P. Relativistic Effects in Chemistry: More Common Than You Thought. Annu. Rev. Phys. Chem. 2012, 63, 45-64.

(114) Pykkö, P. Theoretical Chemistry of Gold. III. Chem. Soc. Rev. 2008, 37.

(115) Dawson, N. J. Lowest-Order Relativistic Corrections to the Fundamental Limits of Nonlinear-Optical Coefficients. Phys. Rev. A 2015, 91, 13832.

(116) Tripathy, K.; Moreno, J. P.; Kuzyk, M. G.; Coe, B. J.; Clays, K.; Kelley, A. M. Why Hyperpolarizabllities Fall Short of the Fundamental Quantum Limits. J. Chem. Phys. 2004, 121, 7932-7945.

(117) Pérez-Moreno, J.; Zhao, Y.; Clays, K.; Kuzyk, M. G. Modulated Conjugation as a Means for Attaining a Record High Intrinsic Hyperpolarizability. Opt. Lett. 2007, 32,59 . 
TOC Graphic:
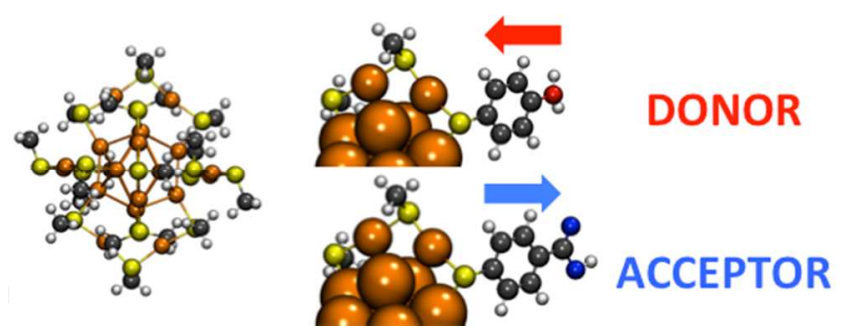

12
13

14

15

16

17

18

19

20

21

22

23

24

25

26

27

28

29

30

31

32

33

34

35

36

37

38

39

40

41

42

43

44

45

46

47

48

49

50

51

52

53

54

55

56

57

58

59

60

ACS Paragon Plus Environment 